The research program of the Center for Economic Studies (CES) produces a wide range of theoretical and empirical economic analyses that serve to improve the statistical programs of the U.S. Bureau of the Census. Many of these analyses take the form of CES research papers. The papers are intended to make the results of CES research available to economists and other interested parties in order to encourage discussion and obtain suggestions for revision before publication. The papers are unofficial and have not undergone the review accorded official Census Bureau publications. The opinions and conclusions expressed in the papers are those of the authors and do not necessarily represent those of the U.S. Bureau of the Census. Republication in whole or part must be cleared with the authors.

\title{
IMPORT PRICE PRESSURE ON FIRM PRODUCTIVITY AND EMPLOYMENT: THE CASE OF U.S. TEXTILES
}

\author{
by \\ Patrick Conway * \\ University of North Carolina at Chapel Hill
}

\section{CES 06-09 March, 2006}

All papers are screened to ensure that they do not disclose confidential information. Persons who wish to obtain a copy of the paper, submit comments about the paper, or obtain general information about the series should contact sang V. Nguyen, Editor, Discussion Papers, Center for Economic Studies, Washington Plaza II, Room 206, Bureau of the Census, Washington, DC 20233-6300, (301-763-1882) or INTERNET address snquyen@ces.census.gov. 


\begin{abstract}
Theoretical research has predicted three different effects of increased import competition on plant-level behavior: reduced domestic production and sales, improving average efficiency of plants, and increased exit of marginal firms. In empirical work, though, such effects are difficult to separate from the impact of exogenous technological progress (or regress). I use detailed plant-level information available in the US Census of Manufacturers and the Annual Survey of Manufacturers for the period 1983-2000 to decompose these effects. I derive the relative contribution of technology and import competition to the increase in productivity and the decline in employment in textiles production in the US in recent years. I then simulate the impact of removal of quota protection on the scale of operation of the average plant and the incentive to plant closure. The methodology employs a number of important innovations in examining the impact of falling import prices on the domestic production of an import-competing good. First, import competition is modeled directly through its impact on the relative prices of monopolistically competitive goods along the lines suggested by Melitz (2000). Second, the effect of technology is incorporated through structural estimation of plant-level production functions in four factors (capital, labor, energy and materials). Solutions to econometric difficulties related to missing capital data and unobserved productivity are incorporated into the estimation technique.

The model is estimated for plants with primary product in SIC 2211 (broadwoven cotton cloth). Results validate modeling demand as for differentiated products. Technological coefficients are sensible, with exogenous technological progress playing a large role. In the simulations run, the effects of foreign price competition are orders of magnitude higher than those of technological progress for the period after quotas on imports are removed. The large-scale reduction in employment and output in the US is shown to be a combination of reduced employment and output at plants in continuous operation and of plant closures that exceed new entries.
\end{abstract}

* The research in this paper was conducted while the author was a Special Sworn Status researcher of the U.S. Census Bureau at the Triangle Census Research Data Center. Research results and conclusions expressed are those of the author and do not necessarily reflect the views of the Census Bureau. This paper has been screened to insure that no confidential data are revealed. The author thanks administrator Kirk White for his advice, and Bidisha Lahiri and Charles Braymen for research assistance. Thanks as well to the Alfred P. Sloan Foundation and the UNC CIBER for financial support. 
Import penetration of US markets and its effect on employment in US plants are flashpoints of the globalization debate. As imports have become more important in US markets, and as US firms have downsized in response to falling demand for their goods, the negative effect of import penetration has become accepted wisdom.

Missing from this debate is any empirical measure of the impact of foreign price competition considered in isolation of technological progress or other explanations for the falling use of labor in textiles in the US. Such a measure must necessarily come from plant-level information. In this paper, I use the Annual Survey of Manufactures and the Census of Manufactures of the US Bureau of the Census to decompose the reduction in textiles employment into parts attributable to international competition, technological innovation, and demand shifts. It extends the previous work in that the import competition/comparative disadvantage explanation will be nested within a model that allows for productivity differences, for technological improvements over time and for profit maximization. It is then used to simulate the impact of removal of import quotas on downsizing and closure of US textiles plants.

This work is done using the Annual Surveys of Manufactures from the US Bureau of the Census for the years 1983-1986, 1988-1991, 1993-1996 and 1998-2000, and the Census of Manufactures from 1982, 1987, 1992 and 1997. The textile industry is examined at the 4-digit SIC level. For the current paper I consider categories 2211 (broadwoven cotton cloth) and 2221 (broadwoven cloth of man-made fibers), but focus in estimation and simulation on SIC 2211.

\section{The argument.}

The central argument of this paper is evident from Figure 1. In the period since 1972, the price of textile imports has fallen relative to the US price index. ${ }^{1}$ This fall in relative price of

\footnotetext{
1 The US CPI index is for all products, and is drawn from the Economic Report of the President 2004. The two relative prices for import categories SIC 2211 and SIC 2221 are the unit values on average for imports into the US. The data for 1972-1988 were supplied by Peter Schott and derived from the trade
} 
imports places pressure on the domestic producers through the price at which domestic products can be sold in the US market. They can respond in three ways: they can accept lower price-cost margins and thus reduce profits (if any), they can improve plant-level productivity, or they can stop production and exit the market. Identifying which response is chosen, and what effects that response has on plant-level production and employment, requires that the response to import competition be modeled simultaneously with the plant's responses to other stimuli: input prices, demand shocks, and exogenous technological progress. In this paper, I derive a methodology for simultaneous estimation in the presence of unobserved plant-level productivity. I estimate the technological parameters of a industry-level production function, and then use that technology to simulate the impact of increased import competition due to removal of quotas.

Figure 1: Evolution of Textile Import Unit Values and the US CPI

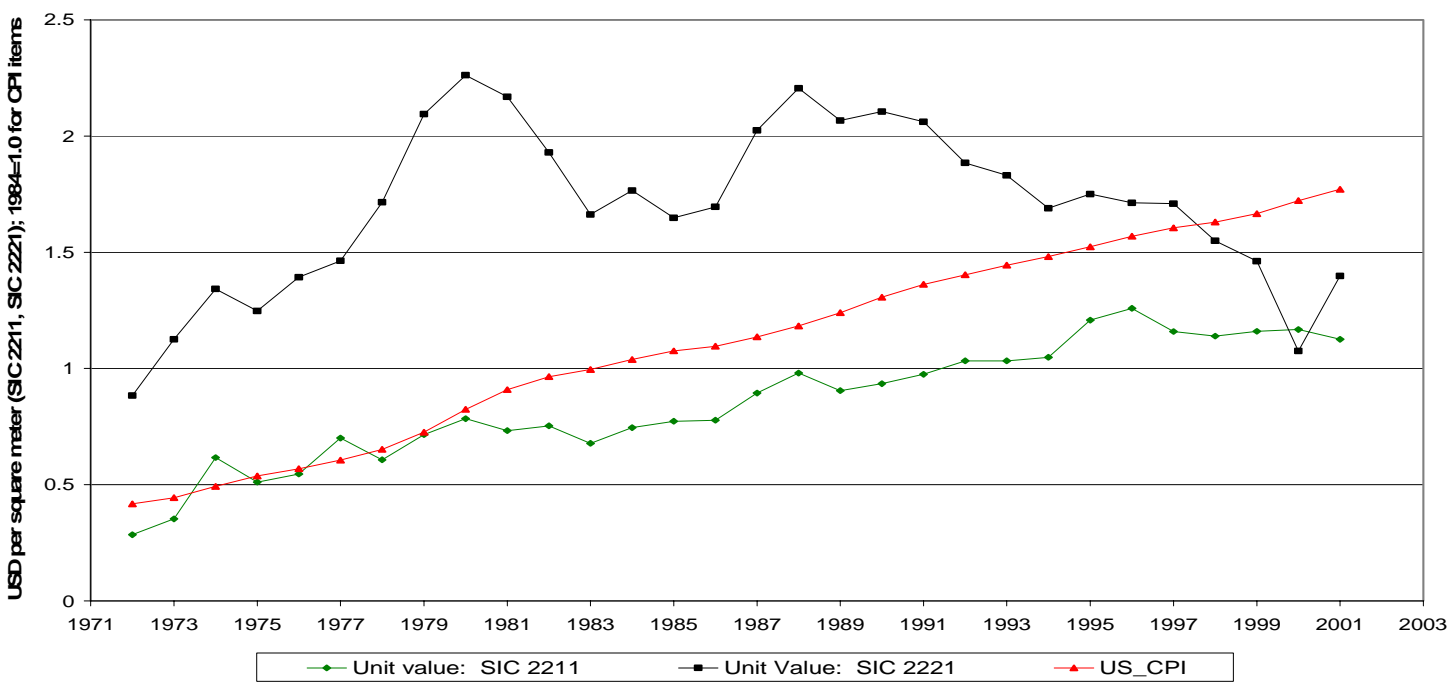

Sources: US ITC Dataweb (for SIC 2211 and SIC 2221) and Economic Report of the President (for US_CPI).

Application to US textiles production. Textiles production is a natural candidate for analysis of the impact of import competition. The US has historically supplied the great majority of its needs for textiles, although in recent years imports from other countries have made

database maintained by Rob Feenstra. The data for 1989-2001 are extracted from the US International Trade Commission database. 
substantial inroads in the market. The product can be measured in a common unit (square meters), allowing derivation of unit values (or unit value indices) for domestic and foreign products.

Textiles are naturally separable by raw material: cotton, man-made fibers, wool, silk and other materials all create textiles with different qualities and different demand among apparel producers. When considering international trade in textiles and the import competition for US producers, the dominant categories are broadwoven cotton textiles and broadwoven textiles of man-made fibers (MMF). These production categories are distinguished by their Standard Industrial Classification (SIC) designations: SIC 2211 for broadwoven cotton textiles and SIC 2221 for broadwoven MMF textiles.

Evidence of import competition. Imports in these two categories followed quite similar patterns in the period $1989-2001$, as is evident in Table 1. In both categories, the value of imports began in excess of $\$ 1$ billion and rose throughout the period until the late 1990s. The largest imports in SIC 2211 occurred in 2000, while for SIC 2221 the high point was reached in 1997. In both cases imports remained near the maximum until a sharp drop in 2001. While imports increased throughout, the share of imports in consumption also rose. In SIC 2211 the percent of imports in total consumption fluctuated between 20 and 33 percent until 2001; in SIC 2221 the percent of imports in total consumption was smaller, fluctuating between 5 and 10 percent until the end of the period.

While imports were increasing in value in both classifications, the average value per square meter in the two classifications follows very different patterns. Figure 2 illustrates this difference in evolution over time for unit values in the two classifications. ${ }^{2}$ For SIC 2211, the unit value of imports rises in 1990 and then declines through 1993. The unit value rose through 1996 , and then stayed roughly constant at $\$ 1.85 / \mathrm{m}^{2}$ thereafter. By contrast, the unit values in

\footnotetext{
2 The value of imports used is the landed duty-paid value of imports; it thus includes both transport costs and tariffs paid to the US.
} 
SIC 2221 were everywhere above those in SIC 2211. They began the period in the neighborhood of $\$ 3.00 / \mathrm{m}^{2}$, but then declined dramatically over the next ten years. In 2001 the unit value of SIC 2221 was $\$ 2.20 / \mathrm{m}^{2}$, not so far above the corresponding unit value in cotton broadwovens.

The nominal price index for domestic production in these two sectors first rose, and then fell, over the sample period. ${ }^{3}$ (For comparison, US CPI rose by about 50 percent over the same period.) Competition, whether from foreign or domestic sources, clearly constrained domestic producers to real reductions in output price. The year 1998 was a turning point in this evolution, with domestic prices falling sharply after that time.

The comparison of domestic and import unit values in SIC 2211 illustrates the typical pattern of import competition: foreign prices begin below US domestic prices, with the differential shrinking over time due to competitive pressure. ${ }^{4}$ The trend rise in import price over time may reflect the trade-diverting impact of the textile quota system; I return to that below. The evolution of domestic and import unit values in SIC 2221 is quite different. Imports began as higher-cost products, and only in the last years of the sample were the two unit values brought into line.

The ratio of unit value of US imports to the index of domestic price will be used as the indicator of import competition. Since I anticipate that the impact of import competition will only be evident for SIC 2221 in the post-1997 period, I report only the results for SIC 2211 in this paper. ${ }^{5}$

\footnotetext{
${ }^{3}$ The domestic price is created from an index based upon that of Bartlesman, Becker and Gray and extended using the estimates of Haltiwanger. The unit value of US exports in these two classifications in 1989 is used as the first observation for the domestic price, and the price index is then used to update the value to subsequent years.

4 The continuing gap between prices could reflect a quality difference in domestic and foreign goods. It could also reflect the quota rents earned by US importers under the Multi-Fiber Arrangement and its successor, the Agreement on Clothing and Textiles.

5 This difference in evolution of unit values is due to the difference in the make-up of textiles goods imported into the US. This is demonstrated by dividing the universe of exporters to the US in these classifications into two groups: developed, and developing (LDC). The countries characterized as "developed" are Australia, Austria, Belgium, Canada, Denmark, France, Germany, Greece, Ireland, Italy, Japan, Liechtenstein, Luxembourg, Monaco, Netherlands, New Zealand, Norway, Portugal, Spain,
} 
Import competition was restrained in this industry during this time period by the existence of bilateral quotas on imports into the US. These bilateral quotas were summarized in the Multi-Fiber Arrangement prior to 1995, and in the Agreement on Clothing and Textiles (ACT) between 1995 and 2005. Not all exporters to the US were governed by these quotas over this period only 19 countries were subject to potentially binding quotas in cotton cloth, and 15 countries subject to potentially binding quotas in cloth of MMF. Table 2 identifies the countries with binding quotas by year. ${ }^{6}$

Figure 2: Domestic Price Index and Unit Value of US Imports

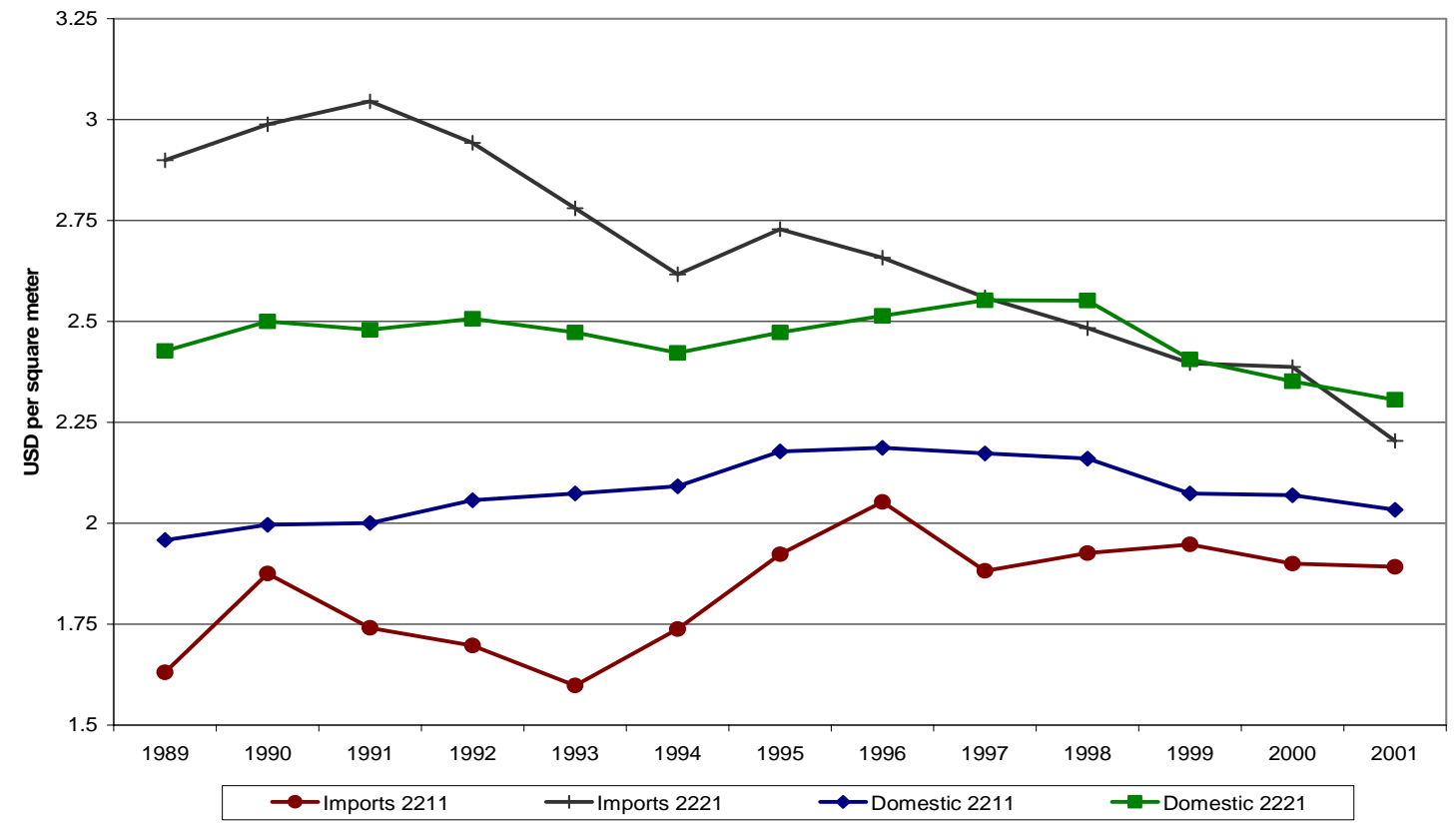

Sources: US ITC Dataweb; Bartlesman, Becker and Gray; and Haltiwanger.

Sweden, Switzerland, and the United Kingdom. When this is done, developed countries were much larger contributors to imports in SIC 2221 than in 2211. Evidence of this point is provided in appendix D.

${ }^{6}$ Quotas generally take one of two forms. There are individual quotas assigned to single quota categories, and Table 2 reports the existence of binding individual quotas by country in at least one of the quota categories. There are also group quotas assigned to span a set of quota categories for each country. A group quota may be binding even if quotas are non-binding in individual quota categories. Binding group quotas are indicated in Table 2 by footnotes. 
When the quota is binding, importers will be unable to source additional cloth from that supplier for cloth in that quota category. Table 2 indicates that in 1993, for example, imports from China, India, Indonesia, Malaysia, Pakistan, Sri Lanka, Thailand and United Arab Emirates were all constrained in at least one of the cotton quota categories, while South Korea was constrained in a broad grouping that included these quota categories. This meant in practice that those wishing to purchase imported cotton cloth would have to turn to other suppliers in that year. Binding quotas were exclusively observed on imports from developing countries during this period. The upward pressure on prices due to binding quotas generated higher unit values on developing-country imports during the period 1993-1999 (for SIC 2211) and 1993-2001 (for SIC 2221). ${ }^{7}$

Evidence of productivity growth in textiles production. As import pressure continued during this period, so also did the opportunities for increased productivity inherent in technological progress in cotton textiles production.

Figure 3: Productivity in US Textiles Production

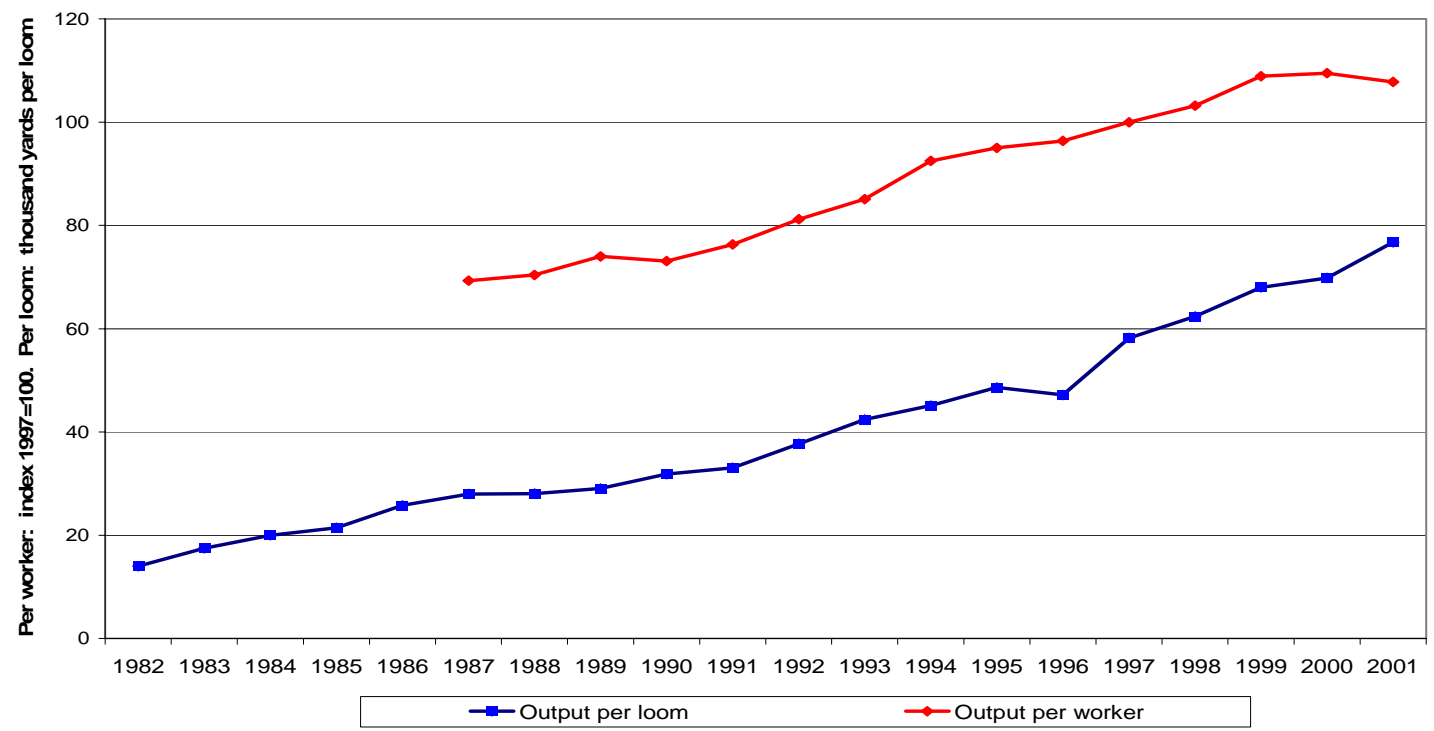

Sources: Current Industrial Reviews, various years, and BLS.

\footnotetext{
${ }^{7}$ Consideration of unit values for developing countries in appendix D supports this conclusion.
} 
Figure 3 illustrates a strong tendency towards technological growth in this industry. ${ }^{8}$ This is labor-saving technological growth, to be sure, as evident in the trend in output per worker. It is also capital-saving technological growth as well, as is evident in the rising ratio of output per loom.

These increases in productivity over time could be due to exogenous technological innovation. They could also be due to the effects of import competition: weeding out of lessproductive firms or increased within-plant efficiency. The remainder of the paper will decompose output and employment growth into the impacts of technological progress and import competition.

\section{Previous research on import competition and domestic productivity.}

Earlier research has put forward two differing hypotheses of the link between import competition and firm-level productivity. The first has been called the "imports as market discipline" approach by Levinsohn (1993) and the "procompetitive effect of trade liberalization" by Devarajan and Rodrik (1989). It is a straightforward application of the discussion of imperfect competition in Dixit and Norman (1980, ch. 9): with more entrants into an imperfectly competitive market, the price-cost margin will be reduced in equilibrium for all competitors and welfare will rise. Levinsohn (1993) and Harrison (1994) test this hypothesis for firm-level evidence in Turkey and Cote d'Ivoire, respectively, and find indirect evidence of price-cost margin compression in firms facing increased competition from imports. ${ }^{9}$

The second hypothesis is more primitive, and suggests that technological efficiency at the plant level will be improved through import competition. Pavcnik (2002) provides a useful example of this approach (and summarizes nicely the previous research). An unobserved

\footnotetext{
${ }^{8}$ The statistics on output per loom are drawn from Current Industrial Reports for broadwoven cotton cloth. The trends for denim are quite similar. The statistics on output per worker are drawn from BLS, and are for all fabric mills (NAICS 3132).

9 The evidence is indirect because it is inferred from coefficients on factor use - there is no direct examination of domestic and foreign prices. Leamer (2004, pp. 341-342) provides a nice summary of this work.
} 
technological parameter of the plant-level production function indexes the productivity of the plant relative to the industry as a whole. Once a plant-level proxy is derived for this unobserved variable, it can be tested in a difference-in-difference framework. Pavcnik (2002) addresses the impact of trade liberalization in Chile: she derives an average productivity indicator for three types of plants (exporter, import-competitor, non-tradable) both at the beginning of trade liberalization and for each year during the trade liberalization. The null hypothesis is that average growth in productivity is insignificantly different across plant type, while the alternative hypothesis is that average growth in productivity in the import-competing industries will be significantly greater than that in the non-tradable industry. Her estimation technique controls for both simultaneity and selection bias and yields proxies for productivity that allow her to reject the null in favor of her alternative hypothesis. ${ }^{10}$ She recognizes the potential importance of the market-discipline argument, but does not control for such effects directly. She does devote substantial effort, however, in contrasting her results with those if the productivity changes were in fact the product of real exchange rate movements - one variant of the market-discipline hypothesis.

Average technological efficiency can be improved in one of two ways: either each plant can raise its productivity, or less productive plants can drop out while more productive plants stay in business (or enter the market). Bernard and Jensen (1998), among others, have associated increased productivity within the plant (or increased X-efficiency, as in Leibenstein (1966)) with improved trade competitiveness, but the direction of causality is typically not well established. Empirical decomposition of this effect requires a frontier production estimation technique, and will not be pursued further here. Increased average technological efficiency due to exit of lessproductive firms is a more common conclusion in the literature. Tybout and Westbrook (1995) found that Mexican plants experienced efficiency gains on average during the trade liberalization

10 She does not have a hypothesis for the relationship between exporters and non-tradables, but does find significant improvement in productivity on average for those plants as well. 
of 1984-1989, and that some of the gains were due to exit of low-productivity plants. However, those facing import competition should have been more likely to exit, and the authors did not find a significant difference between the effect in tradeable-goods sectors and the effect in nontradeables. Trefler (2001) found little evidence from the introduction of the US-Canada free trade area of efficiency gains concentrated in industries with high tariff reductions. Pavcnik (2002) found that exiting plants in Chile during her sample were lower-productivity than continuing plants, but there was no link established between exit and import competition.

There has been some attention to plant-level productivity effects in the literature on the textile industry. Levinsohn and Petropoulos (2001) examine the dynamic evolution of the textiles and apparel industry in the US through examination of plant-level data from the US Census Bureau. While import competition is at the heart of their argument, they do not model this competition directly. They derive a proxy for unobserved productivity using an approach similar (but not identical) to Pavcnik (2002), and then use that proxy to explain the plant-level decision to shut down. Given the lack of modeling of the impact of foreign competition in the market for these goods, the coefficient estimates and the resulting proxy for productivity are both potentially inconsistent. Nevertheless, their estimates of the impact of competition on firm exit are sensible.

The impact of import competition on productivity is identified by Melitz (2003) in a general theoretic model of heterogeneous firms. His focus in Melitz (2003) is on the dynamics of firm entry and exit from market equilibrium, but in Melitz (2000) he expands upon the implications of such a model for plant-level estimation of technological effects in the presence of the market-discipline effects. Baldwin (2005) and Baldwin and Robert-Nicoud (2005) provide a restatement of the implications of the Melitz (2003) model as well as a prediction that the dynamic effects of removing trade barriers may be growth and welfare-reducing due to the reduction in innovation in the sector.

This paper extends those previous in an important dimension. I use plant-level data, but examine a more homogeneous set of plants. By doing so, I will both have more confidence that 
the technological parameters are sensible and will be able to derive direct indicators of import competition. The result of this agenda will be a decomposition of the two complementary effects of trade on plant-level behavior, and a better separation of market-level and plant-level effects of foreign competition. The following theoretical derivation is built upon the Melitz (2000) structure, but extends it by introducing explicitly the relative-price effects due to import competition. The dynamic features of the estimated textiles model provide a good example of the growth-reducing removal of trade barriers noted by Baldwin and Robert-Nicoud (2005).

\section{Decomposing plant behavior into productivity and import- competition effects.}

Consider an industry of imperfectly competitive firms serving a downstream industry (e.g., textiles serving the apparel sector). ${ }^{11}$ Demand for those imperfectly competitive inputs in period $\mathrm{t}$ can be derived from a CES production function for the downstream industry; consider each firm's output $\mathrm{Q}_{\mathrm{it}}$ (with quality $\Lambda_{\mathrm{it}}$ ) as a separate differentiated input with elasticity of substitution $\sigma .{ }^{12}$ The aggregate price index of differentiated inputs is written $\mathrm{P}_{\mathrm{t}}$, the number of upstream firms (and inputs) given by $\mathrm{N}_{\mathrm{t}}$ and the total revenue of all firms in the upstream industry given by $\mathrm{R}_{\mathrm{t}}{ }^{13}$ Denote the logarithm of a variable by its lower-case version. The demand for each differentiated product can then be represented as:

$$
\mathrm{q}_{\mathrm{it}}=\mathrm{r}_{\mathrm{t}}-\mathrm{n}_{\mathrm{t}}-\mathrm{p}_{\mathrm{t}}+(\sigma-1) \lambda_{\mathrm{it}}-\sigma\left(\mathrm{p}_{\mathrm{it}}-\mathrm{p}_{\mathrm{t}}\right)
$$

It is also important to introduce explicitly the distinction between domestic and foreign production of these goods. I separate the firms producing this differentiated product into two groups: group $\mathrm{D}$ of domestic firms, with number $\mathrm{N}_{\mathrm{Dt}}$, and group $\mathrm{F}$ of foreign firms, with number

11 This specification builds upon Melitz (2000).

12 The downstream production function can be written $\mathrm{A}=\left(\Sigma_{\mathrm{i}}\left(\Lambda_{\mathrm{i}} \mathrm{Q}_{\mathrm{i}}\right)^{(\sigma-1) / \sigma}\right)^{(\sigma /(\sigma-1))}$ with summations over $\mathrm{i}$ from 1 through N. It is straightforward to include productivity shifts. Quality differences are more difficult to model, as noted below.

13 The aggregate price index for this CES production function can be written (with summations over 1 through $\mathrm{N}): \mathrm{P}=\left[(1 / \mathrm{N}) \Sigma_{\mathrm{i}} \mathrm{P}_{\mathrm{i}}^{\sigma-1}\right]^{(1 /(\sigma-1))} /\left[(1 / \mathrm{N}) \Sigma_{\mathrm{l}} \Lambda_{\mathrm{l}}^{\sigma-1}\right]^{(1 /(\sigma-1))}$ 
$\mathrm{N}_{\mathrm{Ft} .}{ }^{14}$ Aggregate prices and perceived qualities can be decomposed into these groups as well, with quality-adjusted price indices $\mathrm{P}_{\mathrm{Dt}}$ and $\mathrm{P}_{\mathrm{Ft}}$ as components of aggregate price index $\mathrm{P}_{\mathrm{t}}{ }^{15}$ For firms $\mathrm{i}$ and $\mathrm{j}$, competition is assumed to lead to the following logarithmic relation in qualityadjusted prices:

$$
\mathrm{p}_{\mathrm{it}}-\lambda_{\mathrm{it}}=\tau_{\mathrm{jt}}+\mathrm{p}_{\mathrm{jt}}-\lambda_{\mathrm{jt}}
$$

with $\tau_{\mathrm{jt}}$ the tariff-equivalent measure of the transportation costs and trade barriers that applies in bringing a product $\mathrm{j}$ from the foreign country into the domestic market. For $\mathrm{i}$ and $\mathrm{j}$ both from either group D or group $\mathrm{F}$ and with the simplification on quality in $\mathrm{fn} .5$, this becomes $\mathrm{p}_{\mathrm{it}}=\mathrm{p}_{\mathrm{jt}}{ }^{16}$ For i from group D and $\mathrm{j}$ from group $\mathrm{F}$, it becomes $\left(\mathrm{p}_{\mathrm{it}}-\mathrm{p}_{\mathrm{jt}}\right)=\tau_{\mathrm{jt}}-\ln \left(\mathrm{g}_{\mathrm{t}}\right)$.

Introduction of an additional low-price foreign firm $\mathrm{j}$ reduces the demand for the domestic differentiated product $\mathrm{i}$ in (1) in two ways. First, there is a relative-price effect: the aggregate price index $p_{t}$ falls, reducing $q_{i t}$ for given $p_{i t}$. Second, there is a market-sharing effect: for given real market demand $\left(r_{t}-p_{t}\right)$ the number of firms $n_{t}$ rises, reducing demand for the product of firm i. Both effects will be identified in what follows.

On the production side, the basic estimation model for each plant $\mathrm{i}$ includes the production technology and associated first-order conditions. Define physical output at plant i at time $t$ as $Q_{i t}$. A production function will be defined for $Q_{i t}$ in value added $\left(Y_{i t}\right)$, energy use $\left(E_{i t}\right)$,

14 Of course, $\mathrm{N}_{\mathrm{t}}=\mathrm{N}_{\mathrm{Dt}}+\mathrm{N}_{\mathrm{Ft}}$.

15 These can be defined $\mathrm{P}_{\mathrm{kt}}=\left[\left(1 / \mathrm{N}_{\mathrm{kt}}\right) \sum_{\mathrm{i}} \mathrm{P}_{\mathrm{it}}{ }^{\sigma-1}\right]^{(1 /(\sigma-1))} /\left[\left(1 / \mathrm{N}_{\mathrm{kt}}\right) \sum_{\mathrm{i}} \Lambda_{\mathrm{i}}{ }^{\sigma-1}\right]^{(1 /(\sigma-1))}$ for $\mathrm{k}=\mathrm{D}, \mathrm{F}$. The summations are over the firms $\mathrm{i}$ in the groups $\mathrm{D}$ and $\mathrm{F}$, respectively. The aggregation of domestic and foreign indices into the aggregate is somewhat complex due to the assumption of different perceived qualities. If the only quality distinction (denoted $0<\mathrm{g}_{\mathrm{t}}<1$, with higher $\mathrm{g}_{\mathrm{t}}$ indicating less quality differential) is between foreign and domestic, with $\mathrm{g} \Lambda_{\mathrm{d}}=\Lambda_{\mathrm{f}}$, and if we define $\chi_{\mathrm{t}}=\mathrm{N}_{\mathrm{Dt}} /\left(\mathrm{N}_{\mathrm{Dt}}+\mathrm{N}_{\mathrm{Ft}} \mathrm{g}_{\mathrm{t}}{ }^{\sigma-1}\right)$ as the domestic share of effective firms then $\mathrm{P}_{\mathrm{t}}=\left[\chi_{\mathrm{t}} \mathrm{P}_{\mathrm{Dt}}^{\sigma-1}+\left(1-\chi_{\mathrm{t}}\right) \mathrm{P}_{\mathrm{Ft}}{ }^{\sigma-1}\right]^{(1 /(\sigma-1))}$. For computational ease $\mathrm{I}$ use the geometric mean approximation $\mathrm{P}_{\mathrm{t}} \approx \mathrm{P}_{\mathrm{Dt}}{ }^{\chi} \mathrm{P}_{\mathrm{Ft}}{ }^{1-\chi}$.

16 If the two products are both foreign, but come from different countries, facing different transport costs and tariffs, then the relation is $\mathrm{p}_{\mathrm{it}}=\left(\tau_{\mathrm{jt}}-\tau_{\mathrm{it}}\right)+\mathrm{p}_{\mathrm{jt}}$. 
materials use $\left(\mathrm{M}_{\mathrm{it}}\right)$ and a plant-specific TFP effect $\left(\Pi_{\mathrm{it}}\right) .{ }^{17}$ Value-added is the joint contribution of capital $\left(\mathrm{K}_{\mathrm{it}}\right)$, production labor $\left(\mathrm{L}_{\mathrm{it}}\right)$ and a plant-specific productivity effect $\left(\mathrm{Z}_{\mathrm{i}}\right)$ to output. ${ }^{18} \varepsilon_{\mathrm{it}}$ is a random shock to value-added. This can be written in logarithms:

$$
\begin{aligned}
& \mathrm{q}_{\mathrm{it}}=\mathrm{z}_{\mathrm{i}}+\beta_{\mathrm{y}} \mathrm{y}_{\mathrm{it}}+\beta_{\mathrm{e}} \mathrm{e}_{\mathrm{it}}+\beta_{\mathrm{m}} \mathrm{m}_{\mathrm{it}}+\pi_{\mathrm{it}} \\
& \mathrm{y}_{\mathrm{it}}=\alpha_{\mathrm{k}} \mathrm{k}_{\mathrm{it}}+\alpha_{\mathrm{l}} \mathrm{l}_{\mathrm{it}}+\varepsilon_{\mathrm{it}}
\end{aligned}
$$

Equating supply and demand for each good i defines its equilibrium relative price. This can be rewritten in terms of aggregate domestic price $\mathrm{p}_{\mathrm{Dt}}$.

$$
\left(\mathrm{p}_{\mathrm{it}}-\mathrm{p}_{\mathrm{Dt}}\right)=\left[-\mathrm{q}_{\mathrm{it}}+\left(\mathrm{r}_{\mathrm{t}}-\mathrm{n}_{\mathrm{t}}-\mathrm{p}_{\mathrm{Dt}}\right)+(\sigma-1) \lambda_{\mathrm{it}}\right] / \sigma+\left(\mathrm{p}_{\mathrm{t}}-\mathrm{p}_{\mathrm{Dt}}\right)(\sigma-1) / \sigma
$$

Increases in real net industry sales or product quality will, ceteris paribus, raise the relative price of good i. So also will reductions in the quantity produced, whether due to reduced value-added, reduced energy use or reduced total factor productivity. The market-sharing effect of foreign entrants serves to lower $\mathrm{p}_{\mathrm{t}}$ and the relative price of good $\mathrm{i}$, ceteris paribus.

In Bureau of Census plant-level data, the price of each good is not observed. Instead, the value of sales of the firm $\left(\mathrm{R}_{\mathrm{it}}\right)$ is reported. ${ }^{19}$ As Melitz (2000) points out, estimation must then be based on a "revenue production function". ${ }^{20}$ The technological specification in (3) is supplemented by the effects of total demand, supply and quality on relative price in (5).

$$
\mathrm{r}_{\mathrm{it}}-\mathrm{p}_{\mathrm{Dt}}=\mathrm{q}_{\mathrm{it}}+\left(\mathrm{p}_{\mathrm{it}}-\mathrm{p}_{\mathrm{Dt}}\right)
$$

or, using (5) and the approximation to $\mathrm{P}_{\mathrm{t}}$ in fn. 5:

$$
\mathrm{r}_{\mathrm{it}}-\mathrm{p}_{\mathrm{Dt}}=((\sigma-1) / \sigma)\left[\mathrm{q}_{\mathrm{it}}+\lambda_{\mathrm{it}}\right]+\left(\mathrm{r}_{\mathrm{t}}-\mathrm{n}_{\mathrm{t}}-\mathrm{p}_{\mathrm{Dt}}\right) / \sigma+((\sigma-1) / \sigma)\left(1-\chi_{\mathrm{t}}\right)\left(\mathrm{p}_{\mathrm{Ft}}-\mathrm{p}_{\mathrm{Dt}}\right)
$$

\footnotetext{
17 The presentation here is based on a Cobb-Douglas technology. In estimation, both Cobb-Douglas and translog functions will be employed.

${ }^{18}$ Capital-augmenting and labor-augmenting technology by industry at each time will also be investigated. 19 The Bureau of Census data also aggregates across all products of a specific plant, further complicating estimation. See Melitz (2000) for an extension of the technique to address multi-product firms.

${ }_{20}$ Bernard, Eaton, Jensen and Kortum (2000) provide an alternative approach to modeling imperfect competition, but the Melitz (2000) formulation seemed more appropriate to this market.
} 
The derivation of (7) drives home a number of lessons about estimation with deflated sales data made by Klette and Griliches (1996), Melitz (2000) and Katayama, Lu and Tybout (2003):

- Estimation as if the dependent variable were $\mathrm{q}_{\mathrm{it}}$ would lead to biased estimates of $\beta_{\mathrm{y}}, \beta_{\mathrm{e}}$, $\alpha_{k}, \alpha_{1}$ and $\gamma_{j}$ because the impact of supply expansion on price is ignored. This bias is indicated by the term $((\sigma-1) / \sigma)$.

- Plant-specific productivity effects $\left(\pi_{\mathrm{it}}\right)$ cannot be separated from real or perceived differences in plant-specific quality (e.g., "quality upgrading" in $\lambda_{\mathrm{it}}$ ).

- If average real sales per firm is not used as an explanatory variable, this component will enter the error, most likely imparting serial correlation to those errors.

There is an additional implication here as well, original to this paper and critical to work with traded goods such as textiles. Indicators of international competition should also enter the estimating equation. This is evident in the final term in (7), where the relative-price effect of trade barriers drives a wedge between foreign and domestic prices. $\chi_{\mathrm{t}}$ will be falling over time with foreign firm entry and the exit of domestic firms. It is also evident in the market-sharing effect $\left(r_{t}-n_{t}-p_{D t}\right)$, since the entry of relatively small foreign competitors will lower the average revenue per firm and ceteris paribus lower the deflated sales of firm i. This is the "imports as market discipline" effect, derived at the level of the market. The improved-productivity effect will be embodied in $\pi_{\text {it. }}$

Profit maximization will provide additional structure to estimation. ${ }^{21}$ First-order conditions include the industry-wide logarithmic price of materials $\left(\mathrm{p}_{\mathrm{mt}}\right)$ and the plant-level

\footnotetext{
${ }^{21}$ Firms maximize profits, plants don't, and so the specification given here is an approximation. It will be a good approximation for intratemporal optimization, but may miss product mix-shifting motives for multiplant exit or investment decisions. I investigate that through division of the sample into single-plant and multi-plant firm subgroups and checks for significant coefficient differences for the two subgroups.
} 
logarithmic wages for production workers $\left(\mathrm{w}_{\mathrm{it}}\right)$ and price of energy $\left(\mathrm{v}_{\mathrm{it}}\right) . \quad \varepsilon_{\text {lit, }}, \varepsilon_{\mathrm{eit}}$ and $\varepsilon_{\mathrm{mit}}$ are random errors. ${ }^{22}$

$$
\begin{aligned}
& ((\sigma-1) / \sigma)\left(\mathrm{p}_{\mathrm{it}} / \mathrm{p}_{\mathrm{Dt}}\right) \beta_{\mathrm{y}} \alpha_{1}=\exp \left(\mathrm{w}_{\mathrm{it}}+\mathrm{l}_{\mathrm{it}}\right) / \exp \left(\mathrm{p}_{\mathrm{Dt}}+\mathrm{q}_{\mathrm{it}}\right)+\varepsilon_{\text {lit }} \\
& ((\sigma-1) / \sigma)\left(\mathrm{p}_{\mathrm{it}} / \mathrm{p}_{\mathrm{Dt}}\right) \beta_{\mathrm{e}}=\exp \left(\mathrm{e}_{\mathrm{it}}+\mathrm{v}_{\mathrm{it}}\right) / \exp \left(\mathrm{p}_{\mathrm{Dt}}+\mathrm{q}_{\mathrm{it}}\right)+\varepsilon_{\mathrm{eit}} \\
& ((\sigma-1) / \sigma)\left(\mathrm{p}_{\mathrm{it}} / \mathrm{p}_{\mathrm{Dt}}\right) \beta_{\mathrm{m}}=\exp \left(\mathrm{m}_{\mathrm{it}}+\mathrm{p}_{\mathrm{mt}}\right) / \exp \left(\mathrm{p}_{\mathrm{Dt}}+\mathrm{q}_{\mathrm{it}}\right)+\varepsilon_{\mathrm{mit}}
\end{aligned}
$$

The unobserved variable $\pi_{\text {it }}$ is the measure of productivity necessary for the hypothesis tests described above. Since unobserved, it must be derived as a residual from (3). To obtain consistent estimates of technological coefficients the system (7)-(9) must be estimated, and the market-discipline effect removed.

Use of US Bureau of Census data to estimate this model raises two critical estimating issues. First, the productivity term $\pi_{\mathrm{it}}$ is unobserved, and potentially correlated with $\mathrm{k}_{\mathrm{it}}$ : as Olley and Pakes (1996) and Pavcnik (2002) illustrate, this will introduce bias in the coefficient estimates. Second, there is no reliable series of the value of capital available in the Annual Survey of Manufacturers. ${ }^{23}$ While it is not necessary to my purpose to report precise plant-level measures of $\pi_{\mathrm{it}}$ and $\mathrm{k}_{\mathrm{it}}$, it is necessary to correct for potential bias in estimating the other coefficients of the model.

Problem: unobserved heterogeneity in productivity. The productivity term $\pi_{\text {it }}$ is unobserved and potentially correlated with $\mathrm{k}_{\mathrm{it}}$ : as Olley and Pakes (1996) and Pavcnik (2002) illustrate, this will introduce bias in the coefficient estimates. In the current model, the sources of bias are concentrated in the term $\psi_{\text {it. }}$

$$
\begin{aligned}
q_{i t}=z_{i}+\psi_{i t}+\beta_{\mathrm{e}} e_{i t}+\beta_{\mathrm{m}} \mathrm{m}_{\mathrm{it}}+\beta_{\mathrm{y}} \alpha_{1} 1_{\text {it }} \\
\psi_{\text {it }}=\beta_{\mathrm{y}} \alpha_{\mathrm{K}} k_{\mathrm{it}}+\pi_{\mathrm{it}}+\beta_{\mathrm{y}} \varepsilon_{\mathrm{it}}
\end{aligned}
$$

\footnotetext{
${ }^{22}$ In all three equations, the elasticity of aggregate price with respect to increases in the single firm's factor use is excluded as second-order in size.

23 Capital data are available for the Census of Manufactures years, and these will be used in what follows.
} 
While $\pi_{\mathrm{it}}$ is unobserved, two observed plant-level decisions provide information about it. ${ }^{24}$

- First, the firm will choose to invest $\left(\mathrm{i}_{\mathrm{it}}\right)$ if assured of adequate return on investment: the quantity invested will depend upon unobserved productivity as well as the capital stock and plant-specific effect $\mathrm{z}_{\mathrm{i}}: \mathrm{i}_{\mathrm{it}}=\mathrm{i}\left(\mathrm{k}_{\mathrm{it}}, \pi_{\mathrm{it}}, \mathrm{z}_{\mathrm{i}}\right)$

- Second, the firm's decision to continue operations in the next period is a function of its profitability: this profitability is a function of $\pi_{\mathrm{it}+1}$ and $\mathrm{k}_{\mathrm{it}+1}$ as well as a plant-specific profitability factor $\mathrm{z}_{\mathrm{i}}$. The probability of continuation (or survival) $\mathrm{ps}_{\mathrm{it}}$ is then $\mathrm{ps}\left(\pi_{\mathrm{it}+1}, \mathrm{k}_{\mathrm{it}}\right.$, $\left.\mathrm{i}_{\mathrm{t}}, \mathrm{z}_{\mathrm{i}}\right)$.

Following Pavcnik (2002), I assume that the investment decision is monotonically increasing in unobserved productivity and invert the investment function. This provides an expression for $\pi_{\mathrm{it}}$ that can be substituted into $\psi_{\mathrm{it}}$. To estimate, I use a series expansion $\Omega\left(\mathrm{k}_{\mathrm{it}}, \mathrm{i}_{\mathrm{it}-1}\right)$ in place of $\psi_{\mathrm{it}}$ in defining $\mathrm{q}_{\mathrm{it} .}{ }^{25}$

$$
\mathrm{q}_{\mathrm{it}}=\mathrm{z}_{\mathrm{i}}+\Omega\left(\mathrm{k}_{\mathrm{it}}, \mathrm{i}_{\mathrm{it}-1}\right)+\beta_{\mathrm{e}} \mathrm{e}_{\mathrm{it}}+\beta_{\mathrm{m}} \mathrm{m}_{\mathrm{it}}+\beta_{\mathrm{y}} \alpha_{1} 1_{\mathrm{it}}+\beta_{\mathrm{y}} \varepsilon_{\mathrm{it}}
$$

There is as well potentially a survival bias in the data due to the exit of firms. This causes a nonzero mean of the unobserved $\varepsilon_{\mathrm{it}}$, and this effect is corrected through inclusion of the inverse Mills ratio $\kappa_{\mathrm{it}}$ from the probit estimation of the exit decision. Incorporation of $\mathrm{q}_{\mathrm{it}}$ from (12) and $\kappa_{\mathrm{it}}$ into (7) permits consistent estimation of $\beta_{\mathrm{e}}, \beta_{\mathrm{m}}$ and $\beta_{\mathrm{y}} \alpha_{1}$. through the system (8), (9), (10) and (13).

$$
\mathrm{r}_{\mathrm{it}}-\mathrm{p}_{\mathrm{Dt}}=((\sigma-1) / \sigma)\left[\mathrm{q}_{\mathrm{it}}+\lambda_{\mathrm{it}}\right]+\left(\mathrm{r}_{\mathrm{t}}-\mathrm{n}_{\mathrm{t}}-\mathrm{p}_{\mathrm{Dt}}\right) / \sigma
$$

24 The firm will choose to invest if it can be assured of adequate return on investment. The quantity invested will depend upon the unobserved productivity as well as the existing capital stock and a plantspecific factor.

$$
\mathrm{i}_{\mathrm{it}}=\lambda\left(\pi_{\mathrm{it}}, \mathrm{k}_{\mathrm{it}}, \mathrm{z}_{\mathrm{i}}\right) \quad \lambda_{1}>0, \lambda_{2}<0, \lambda_{3}>0
$$

If the binary variable $X_{i t}$ takes a value of one for a firm exiting in $t+1$, the exit decision could be written:

$$
\begin{aligned}
X_{i t} & =1 \text { for } g\left(E\left(\pi_{i t+1}\right), k_{i t+1}, z_{i}\right)>0 \\
& =0 \text { otherwise }
\end{aligned}
$$

The resulting survival propensity links expected productivity with investment.

$$
\mathrm{ps}_{\mathrm{it}}=\theta\left(\pi_{\mathrm{it}+1}, \mathrm{k}_{\mathrm{it}}+\mathrm{i}_{\mathrm{it}}, \mathrm{z}_{\mathrm{i}}\right) \quad \theta_{1}>0, \theta_{2}>0, \theta_{3}>0
$$

The inverse Mills ratio $\mathrm{v}_{\mathrm{it}}$ is also derived from this estimation.

25 I will use the notation $\Omega\left(\mathrm{x}_{\mathrm{a}}, \mathrm{x}_{\mathrm{b}}\right)$ to represent a third-order series expansion in the arguments $\mathrm{x}_{\mathrm{a}}$ and $\mathrm{x}_{\mathrm{b}}$. Separate coefficients are estimated on each component of the expansion. Since these are not interpretable from theory, I do not report these coefficients. They are available on demand. Expansion of other orders yielded similar results. 


$$
+((\sigma-1) / \sigma)\left(1-\chi_{t}\right)\left(p_{F t}-p_{D t}\right)+\mu \kappa_{i t}
$$

Define the consistent estimates of $\beta_{\mathrm{e}}, \beta_{\mathrm{m}}$ and $\beta_{\mathrm{y}} \alpha_{1}$ as $b_{\mathrm{e}}, \mathrm{b}_{\mathrm{m}}$, and $\mathrm{b}_{\mathrm{y}} \mathrm{a}_{1}$ respectively. An estimate of $\psi_{\mathrm{it}+1}$, defined $\mathrm{f}_{\mathrm{it}+1}$, is then

$$
f_{i t+1}=q_{i t+1}-b_{e} e_{i t+1}-b_{m} m_{i t+1}-b_{y} a_{1} 1_{i t+1}
$$

Using (11), we can rewrite this in terms of next-period productivity:

$$
\beta_{\mathrm{y}} \pi_{\mathrm{it}+1}=\mathrm{f}_{\mathrm{it}+1}-\mathrm{z}_{\mathrm{i}}-\beta_{\mathrm{y}} \alpha_{\mathrm{k}} \mathrm{k}_{\mathrm{it}+1}-\beta_{\mathrm{y}} \varepsilon_{\mathrm{it}+1}
$$

The productivity $\pi_{\mathrm{it}+1}$ is unobserved. If unobserved productivity is assumed to follow a random walk for each firm, then ${ }^{26}$

$$
\pi_{\mathrm{it}+1}=\pi_{\mathrm{it}}+\zeta_{\mathrm{it}}
$$

The data sample is censored by including only those plants that continue. If unobserved productivity is positively correlated with continuation, then those exiting the sample will have disproportionately negative shocks $\varsigma_{\text {it }}$. To control for this upward bias in continuing firms I model next-period productivity as a series expansion in unobserved productivity $\mathrm{p}_{\text {it }}$ and the probability of continuation $\mathrm{ps}_{\mathrm{it}}$. The estimation equation for the capital coefficients becomes as in (16), while the investment decision of the plant (17) is estimated simultaneously. In addition to capital, lagged investment and the unobserved productivity term, I include the aggregate capacity utilization in apparel $\left(\mathrm{cu}_{-} \mathrm{a}_{\mathrm{t}}\right)$ and aggregate capacity utilization in textiles $\left(\mathrm{cu}_{-} \mathrm{t}_{\mathrm{t}}\right)$ in the US as variables to measure potential market-pressure effects on the investment decision.

$$
\beta_{\mathrm{y}} \Omega\left(\mathrm{up}_{\mathrm{it}}, \mathrm{ps}_{\mathrm{it}}\right)=\mathrm{f}_{\mathrm{it}+1}-\mathrm{z}_{\mathrm{i}}-\beta_{\mathrm{y}} \alpha_{\mathrm{k}} \mathrm{k}_{\mathrm{it}+1}-\beta_{\mathrm{y}}\left(\varepsilon_{\mathrm{it}+1}+\varepsilon_{\pi \mathrm{it}}\right)
$$

with

$$
\begin{aligned}
& \dot{i}_{\text {it }}=\eta_{\mathrm{o}}+\eta_{1} \mathrm{k}_{\mathrm{it}}+\eta_{2} \mathrm{i}_{\mathrm{it}-1}+\eta_{3} \mathrm{up}_{\mathrm{it}}+\eta_{4} \mathrm{cu} \mathrm{a}_{\mathrm{t}}+\eta_{5} \mathrm{cu}_{-} \mathrm{t}_{\mathrm{t}}+v_{\mathrm{it}} \\
& \mathrm{up}_{\mathrm{it}}=\Omega\left(\mathrm{k}_{\mathrm{it}}, \mathrm{i}_{\mathrm{it}-1}\right)-\beta_{\mathrm{y}} \alpha_{\mathrm{k}} \mathrm{k}_{\mathrm{it}}
\end{aligned}
$$

The coefficients $\beta_{\mathrm{y}} \alpha_{\mathrm{k}}$ and $\eta_{\mathrm{o}}$ through $\eta_{5}$ are estimated consistently with this joint estimation procedure. The standard errors of coefficients estimated in the two stages will not be consistently

26 In estimation, I allow for a time-invariant fixed effect as well as a component following this random walk. 
estimated, and so I use a bootstrap exercise to derive consistent standard errors. These are reported in the tables that follow.

Problem: missing capital stock. Reliable estimates of $\mathrm{k}_{\mathrm{it}}$ are only available each five years when the Census of Manufactures (CM) is conducted. The Annual Survey of Manufacturers (ASM) reports values for capital, but the source is undocumented and the reliability is suspect. ${ }^{27}$ I create an estimate of the capital stock using the perpetual inventory method with capital values reported in the CM and the investment values reported in the ASM.

Capital is assumed to evolve according to $\mathrm{K}_{\mathrm{it}+1}=(1-\delta) \mathrm{K}_{\mathrm{it}}+\mathrm{I}_{\mathrm{it}}$, where $\mathrm{K}_{\mathrm{it}}$ and $\mathrm{I}_{\mathrm{it}}$ indicate real capital and real investment, respectively, at time $t$ and $\delta$ represents a time and plant-invariant depreciation rate of capital. Nominal values of capital and investment reported by the Census are deflated into real values using the deflators constructed by Bartlesman, Becker, and Gray. ${ }^{28}$ The depreciation rate $\delta$ is estimated from a combined panel of ASM and CM observations of plants that reported a capital stock in more than one CM year. For example, if a plant reported its capital stock in the CM of 1987 and 1992, and investment for the years 1987 to 1991, then the plant's data are used to estimate the depreciation rate. The depreciation rate is estimated via nonlinear least squares as

$$
\mathrm{K}_{\mathrm{it}}=(1-\delta)^{5} \mathrm{~K}_{\mathrm{it}-5}+(1-\delta)^{4} \mathrm{I}_{\mathrm{it}-4}+(1-\delta)^{3} \mathrm{I}_{\mathrm{it}-3}+(1-\delta)^{2} \mathrm{I}_{\mathrm{it}-2}+\mathrm{I}_{\mathrm{it}-1}
$$

The estimate of the depreciation rate is reported in Table 4 for both of the 4-digit industries examined. This estimate is then used to project the capital stock for each plant into previous and future years using the evolution of capital in (18) and the observed investment rates. These predicted real values of capital are created for all plants with at least one CM response.

${ }^{27}$ The ASM data files include information on the value of capital. The Census documentation says that the capital variables TAB and TAE were not collected in the ASM years 1986, 1988-1991, and 1993-1996. However, these variables are populated for almost all plants in those years, and most of the plants have non-zero values. The reliability of the reported values is suspect. For example, in 12 percent of the plantlevel observations for SIC 2211, nominal capital at the beginning of the year is reported to be less than nominal investment in the previous year.

28 The Bartlesman-Becker-Gray data are available from the NBER website. These data includes price indices through 1996. For the remaining years in the sample, 1997-2001, the capital stock and investment are deflated using the consistent price indices created by John Haltiwanger and available from his website. 
For example, if a plant reported its capital stock in the $1992 \mathrm{CM}$, then this level is used as the plant's base year capital stock in the creation of the plant's capital stock in ASM years. If a plant was not observed in the $1992 \mathrm{CM}$, then the plant's 1987 capital stock as reported by the CM is used as its base year capital stock. Likewise, if the plant was not present in the 1987 or 1992 CM, then the plant's 1997 CM capital stock was used as the base year in the creation of the plant's capital stock. The depreciation rate estimated using this technique is 0.08 for both SIC 2211 and SIC $2221 .^{29}$

While this methodology represents a consistent use of the available data, its results leave room for improvement. One test for the methodology is to use the perpetual inventory method to create the estimated capital stock and then compare that estimate to the actual reported capital stock in CM years. The correlation of actual and predicted in 1997 for those with capital stock based on 1992 observations is 0.84 (in SIC 2211) and 0.80 (for SIC 2221) while the correlation of actual and predicted in 1987 is 0.64 and 0.80 (for SIC 2211 and 2221, respectively).

\section{Estimation results.}

I estimate the model represented by equations (7) through (9) using data for large US textile plants. The plants are those included in the ASM and CM. Table 3 reports the number of firms and the average revenue (known as total value of shipments) per firm in the sample for each year. As is evident in Table 3, the firms sampled in years ending in "2" and "7" are more numerous and smaller on average from those in other years - those are the CM years, and include more small plants. In estimation, those firms only sampled during CM years are excluded. Plants

29 Given the time series of observations, it is possible to test for the constancy of $\delta$ across the sample. If separate estimates of $\delta$ are estimated for the 1987-1992 and for the 1992-1997 periods, they prove to be significantly different from one another in SIC 2211, but insignificantly different from one another in SIC 2221. Use of a capital stock estimate that incorporates these differences in $\delta$ across time does not change the substantive results of the estimation that follows. 
are matched across years to create a panel of data. ${ }^{30}$ I use data from the years 1983-2001 for a total of 19 years of data.

Production function. I retain the demand specification used in the theoretical derivation above, but use both the Cobb-Douglas and the more general translog specification of productive technology outlined in Table A1. Four inputs are considered in production: capital, labor, electricity and materials. Parameter restrictions to impose constant returns to scale are imposed in all versions of the model, as are first-order conditions for labor, electricity and materials. Time trends are introduced to allow for technological progress. The foreign price $\mathrm{P}_{\mathrm{ft}}$ is represented by the average real unit value of imports in that SIC classification.

Table 5 reports the results from estimating equations (7) through (10) for the plants producing broadwoven cotton fabric (SIC 2211). The translog technology of Appendix A is assumed. The first two columns report estimation of the equation system under the simple assumption that capital is exogenous to the decision - in other words, ignoring the bias due to unobserved productivity. The first column conducts that estimation with no fixed effect terms $z_{i}$, while the second column includes $\mathrm{z}_{\mathrm{i}}$ as components of the production technology. In both cases, the corresponding first-order conditions are imposed. The third column reports the coefficient estimates when unobserved productivity is accounted for as in equations (11) through (17). Analogous estimation results for a Cobb-Douglas technology are reported in Table A2. The standard errors of the two-step estimation procedure reported in the last column are derived through bootstrapping using 100 draws on the errors. ${ }^{31}$

\footnotetext{
30 I create the sample in two steps. First, I identify every plant in the CM and ASM samples for 1983 through 1999 inclusive that identifies itself as having SIC 2211 as a primary product. Second, I use the product trailers for 2000 and 2001 to identify those plants with cotton-based fabric as primary product. (In those years, the SIC classification is no longer used.) These are the plants with SIC 2211 for estimation of production technology.

31 The bootstrapping procedure is as follows. First, the two-step estimation procedure is completed, and the parameter estimates derived. These estimates are then employed with actual explanatory variables to obtain predicted values for each observation. Actual minus predicted yields the errors. A bootstrapping sample is created by drawing at random (with replacement) from the pool of errors and then adding that random error to the predicted values. The resulting series of the dependent variable is used to re-estimate
} 
There are three important features of the production technology and market characteristics of SIC 2211.

- The estimate of the elasticity of substitution across suppliers is relatively high (around 14) and is precisely estimated. This indicator of a highly elastic market implies that small increases in the relative price of domestic goods to foreign goods will cause large shifts in market share toward the foreign producers.

- The technological coefficients take reasonable values for the most part. Of special interest is the statistical significance of coefficients $b_{1}$ through $b_{10}$ : these are assumed to be zero by the Cobb-Douglas formulation, but play an obvious role here. Table A2 in Appendix A reports the (production-weighted) average shares of the factors of production in total revenue. While the shares are somewhat stable over time, there is sufficient variation to make the translog the preferred specification.

- International trade pressures on these firms enter through the high elasticity of substitution of demand for their products. The impact of technological growth is evident in the direct time effects $\left(a_{9}-a_{10}\right)$ and in the indirect effects through the marginal productivity of the four factors $\left(b_{7}-b_{10}\right)$. While the direct effect of technological progress is positive $\left(\mathrm{a}_{9}\right)$, the indirect effects through reduced marginal productivity of factors over time $\left(b_{7}-b_{10}\right)$ are negative.

There are odd features of these results as well, like the insignificant capital coefficient $\left(a_{k}\right)$ in the two-step estimation. ${ }^{32}$ Multi-plant firms differ insignificantly from the unit-plant firms in production technology.

Investment decision. The investment decision is a function of unobserved productivity, and as such should be estimated simultaneously with that measure. When (14) through (17) are

the two-step procedure. After 100 samples are drawn and re-estimated, the estimated distribution of the coefficients is used to derive the standard errors in the table.

32 This does not emerge in the Cobb-Douglas estimation for SIC 2211 reported in Table A1. There the capital coefficient, and indeed all factor coefficients, is quite stable across estimation techniques. 
estimated, the capital-related coefficients of the third column of Table 5 are the outcome. So also is a behavioral equation for investment. The results of this estimation are reported in Table 6 . Investment is rising with the capital stock of the plant, and also with the lagged investment decision, with the latter effect both significantly and precisely estimated. Unobserved productivity has the expected positive correlation with investment, as the more productive a plant the higher the return on investment. The capacity utilization rates in the apparel and textiles industries enter insignificantly, but with the opposite sign to that expected.

Entry and exit decisions. Plants may be created equally, but their propensities to enter and exit vary systematically with the pressures of international competition. Exit and entry will in equilibrium also support the division of suppliers between domestic and foreign. The elasticity of substitution defines a relation between the numbers and output of domestic and foreign suppliers:

$$
\begin{aligned}
& \left(\mathrm{N}_{\mathrm{Ft}} \mathrm{Q}_{\mathrm{Ft}} / \mathrm{N}_{\mathrm{Dt}} \mathrm{Q}_{\mathrm{Dt}}\right)=\mathrm{d}_{\mathrm{o}}\left(\mathrm{P}_{\mathrm{Dt}} / \mathrm{P}_{\mathrm{Ft}}\right)^{\sigma} \\
& \chi_{\mathrm{t}}=\left(\mathrm{N}_{\mathrm{Dt}} \mathrm{Q}_{\mathrm{Dt}} /\left(\mathrm{N}_{\mathrm{Dt}} \mathrm{Q}_{\mathrm{Dt}}+\mathrm{N}_{\mathrm{Ft}} \mathrm{Q}_{\mathrm{Ft}}\right)\right)=\left(1 /\left(1+\mathrm{d}_{\mathrm{o}}\left(\mathrm{P}_{\mathrm{Dt}} / \mathrm{P}_{\mathrm{Ft}}\right)^{\sigma}\right)\right)
\end{aligned}
$$

A fall in $\mathrm{P}_{\mathrm{Ft}}$ relative to $\mathrm{P}_{\mathrm{Dt}}$, for example, will lead to a reduction in the share $\chi_{\mathrm{t}}$ of sales from domestic plants, with that reduction increasing with the size of $\sigma$. Those factors that affect the relative size of $\mathrm{Q}_{\mathrm{Dt}}$ and $\mathrm{Q}_{\mathrm{Ft}}$ will also have an effect on exit and entry as measured by changes in $\mathrm{N}_{\mathrm{Dt}}$ and $\mathrm{N}_{\mathrm{Ft}}$.

Other systematic reasons for exit are derived from estimation of the propensity to exit, with results reported in Table 7. The preceding estimation results were based on self-reported sampling: if the plant reported that its primary product was from SIC 2211 in that year, it was used in estimation for the SIC 2211 model in that year. However, it is not difficult for the typical plant to shift from SIC 2211 to SIC 2221 products and back again. Determining the appropriate measures of exit and entry into this market is as a result complicated by the possibility of switching production to the other product category. There is no simple way to sort the US Census 
databases to provide a consistent panel of data on textiles firms across time. ${ }^{33}$ To create such a panel, I used the following two-step procedure with the data drawn from the ASM and CM for the period 1982-2001.

- In a first step, all plant/year observations not identifying their primary product as either SIC 2211 or SIC 2221 (or its counterpart for 2000 and 2001) in the ASM were excluded. These data were then sorted by PPN, and a list of all PPN observed in the aggregated data was compiled.

- In the second step, I returned to the complete ASM and CM for 1982-2001. I culled the subset of data for plants with these PPN, whether or not they listed SIC 2211 or SIC 2221 as primary product in that year.

This two-step process provided 6322 plant/year observations. The initial search over the ASM alone was designed to exclude smaller manufacturing plants that would be observed only in $\mathrm{CM}$ years. The plants retained were expected to respond on an annual basis to the Census, thus creating a panel data set. In practice, there was substantial evidence of non-response.

Entry and exit are then defined as the first appearance and final appearance of the PPN in the sample. In cases in which there are multi-year gaps between observations of the same PPN, the beginning of the gap is not treated as an exit. Further, entry and exit refer here to entering or leaving the joint textiles category including all plants with at least one year of primary production in SIC 2211 or SIC 2221. The exit propensity is modeled as a function of year-specific and US state-specific dummy variables, to capture unobserved time or place-specific influences. Of the

33 In principle, there is a simple sort possible. The CM/LRD is a large-scale survey of manufacturers occurring every 5 years. The ASM/LRD is a smaller-scale survey of a subset of large manufacturers. The US Census categorizes each plant by a weight: if the weight is one, the plant is certain to be invited to complete the survey each ASM/LRD year. If the weight is less than one, then the weight represents the probability that the plant will be invited to complete the survey in any ASM/LRD year. All manufacturers are invited to complete the survey in CM/LRD years, but for the smallest the survey is abridged. These "administrative record" responses are also excluded from the sample used here by the sorting used here. It is unfortunately the case that many plants in this category nevertheless do not have responses tabulated at the US Census for all years. There are two potential reasons: either the Census reclassified the plant at some point in the period from certain response to probabilistic response, or the plant simply refused to (or forgot to) submit the information in a given year. 
remaining variation in propensity to exit, the $(\log )$ ratio of domestic and foreign final-good prices is the only significant factor. There is thus an exit effect of import competition even when estimated simultaneously with other potential determinants of exit. As foreign prices go up relative to domestic prices, the propensity to exit declines. The "real" prices of the factors of production (materials price, energy price and wage) all enter with the expected positive sign, but none is significant. ${ }^{34}$

It is impossible to identify a similar propensity to enter, as the universe of potential entrants is not observed. Instead, treating all potential entrants as identical, I estimate Poisson count regressions to explain the number of entering plants observed in each year. The results from this estimation are reported in Table 8. A higher relative price of foreign goods encourages entry with large and significant coefficient. The larger average size of plants (as measured by average real revenues) significantly reduces the number of entrants. Surprisingly, the real prices of labor, materials and energy also enter with positive coefficient; this is inconsistent with the "ceteris paribus" predictions of profit-maximization, but could be due to the churning effect (high exit leading to high entry) of these relative prices. The capacity utilization ratios in textiles and in apparel have, ceteris paribus, an insignificant effect on the number of entrants.

Evolving average productivity. There is striking heterogeneity of firms in these samples. Figure 4 illustrates the kernel density function generated from the distribution of fixed effects for the 186 plants observed in sector SIC 2211. There is a pronounced tail at the lower (i.e., less productive) end of the spectrum, but the majority of firms fall in an intermediate range between 1.8 and 2.5. The most productive are massed in the upper tail.

Figure 4

\footnotetext{
${ }^{34}$ This predicted propensity to exit is used in the inverse Mills ratio correction in Table 5 . It will be 1 minus the probability of continuation $\operatorname{ps}\left(\pi_{\mathrm{it}+1}, \mathrm{k}_{\mathrm{it}}, \mathrm{i}_{\mathrm{t}}, \mathrm{z}_{\mathrm{i}}\right)$ cited above.
} 


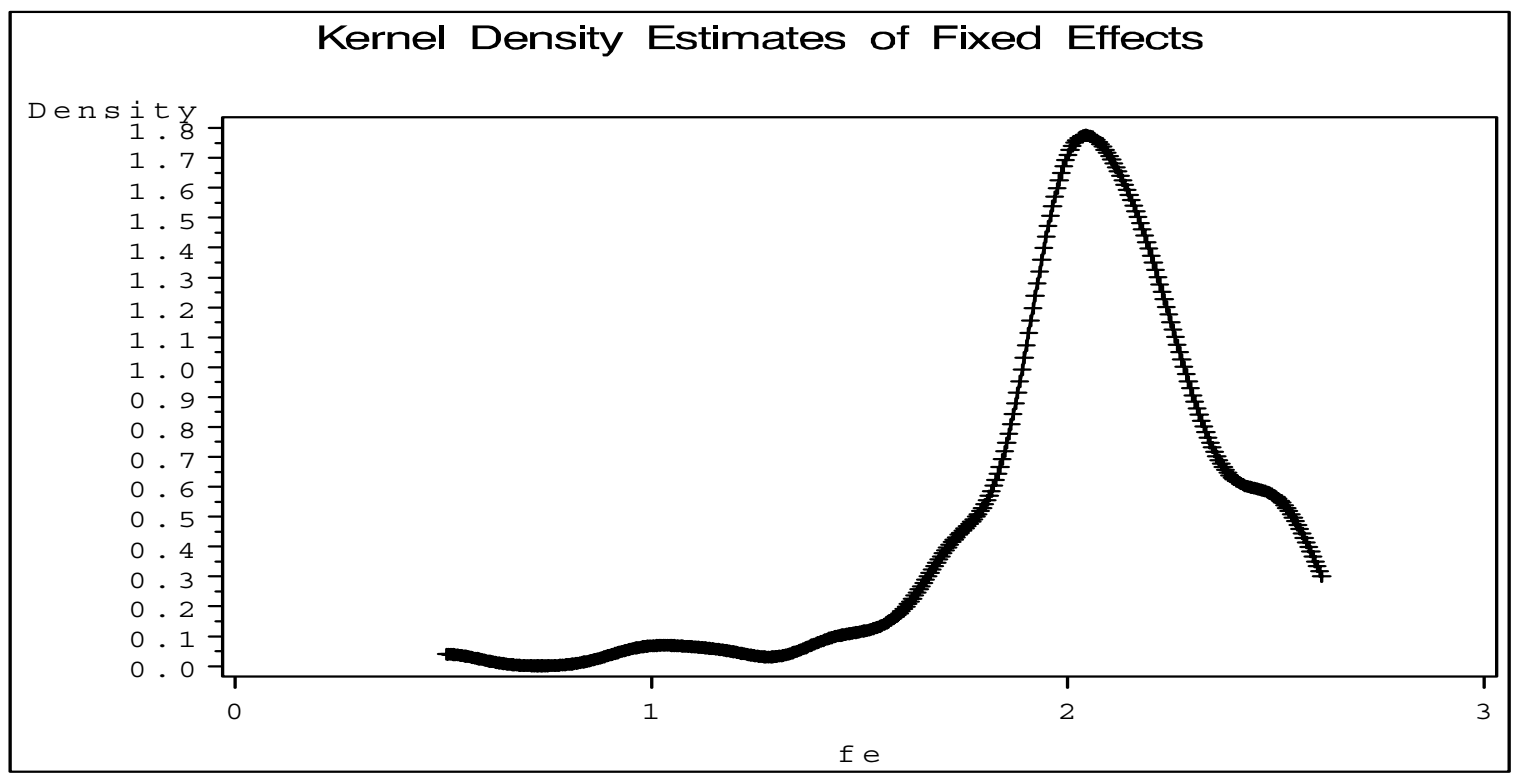

Exogenous growth in total factor productivity has already been accounted for in the non-linear time effects of the estimation, and the "imports as discipline" effects are captured in the relativeprice term. There is also an increased average productivity observed due to the selection effect as lower-productivity plants exit, the average productivity of those remaining will rise. This is indicated by the coefficient on the inverse Mills ratio $\kappa_{\mathrm{it}}$. Table 9 reports the average value of $\kappa_{\mathrm{it}}$ as well as the number of plants in the sample. In the earlier period (i.e., pre-1995) the steadily expanding US economy and the protection offered from import competition led to a rising number of domestic plants. This was also a period of little exit, with even low-productivity plants remaining in production. The average probability of exit rose, leading to a rise as well in $\kappa_{\mathrm{it}}$ on average. After that time the degree of import competition rose and the low-productivity firms were pared away through exit. As this occurred, the number of firms and average $\kappa_{\mathrm{it}}$ both fell. In terms of Figure 4, the earlier period was one in which plants in the lower end of the distribution remained in business. The later period was characterized by the paring off of this lower tail through exit. By the end, as Table 9 shows, there is less selection bias on average in estimation due to plant exit - because the plants with lower productivity had already exited.

I summarize the estimation results as follows. 
- Technological progress enters both directly (i.e., Solow-neutral growth) and indirectly as embodied in the four factors of production. This is the exogenous productivity effect, and is quite significant in this industry.

- The price elasticity of substitution of one supplier for another is quite high. In this type of market a reduction in the relative price of imported textiles will lead to an increase in total sales but an increase as well in the foreign share of the market. Domestic production will fall as a consequence. This is the "imports as market discipline" effect, and it is large and significant.

- Increased import price competition raises the exit rate for US plants and lowers the entry rate. The net effect will be a significant shrinking of the number of plants in the industry.

- There is evidence as well of significant effects (first negative, then positive) on average plant productivity over time. Given the controls in place for other determinants, I interpret these positive effects in the later years as gains in average productivity due to exit of the lower-productivity plants.

While each of these is of interest, the relative quantitative contribution of each is unclear. In the following section I simulate the model to derive relative effects of the three channels for import competition to affect output and employment.

\section{Simulation results.}

The model estimated above allows simulations of the impact of import competition that can be separated from the impact of technology. I exploit this property in projecting the impact of increased price competition in broadwoven cotton textiles with the removal of quotas on imports. This is not designed to replicate US experience in the period 2001-2005, but rather to illustrate the decomposition possible between import competition and technology effects in response to a foreign price shock. For each simulation, I use the translog estimates of Table 5, 
column 2, to represent the technology. For the elasticity of substitution between imports and domestic goods I use the value of 14.39 reported in Table 5. I focus upon the production and employment implications of the model in the discussion that follows, although similar analyses are of course possible on energy use, intermediate inputs or investment.

Figure 5 illustrates the actual and predicted values of median real sales per plant in SIC 2211 for the in-sample period 1983-2000. There are two series reported in logarithmic form: actual median sales per plant, and simulated sales per plant. The model-based estimate matches the median real sales per plant well throughout the sample, with largest deviation in $1996 .{ }^{35}$

Figure 5: Model Simulations, SIC 2211, Sales

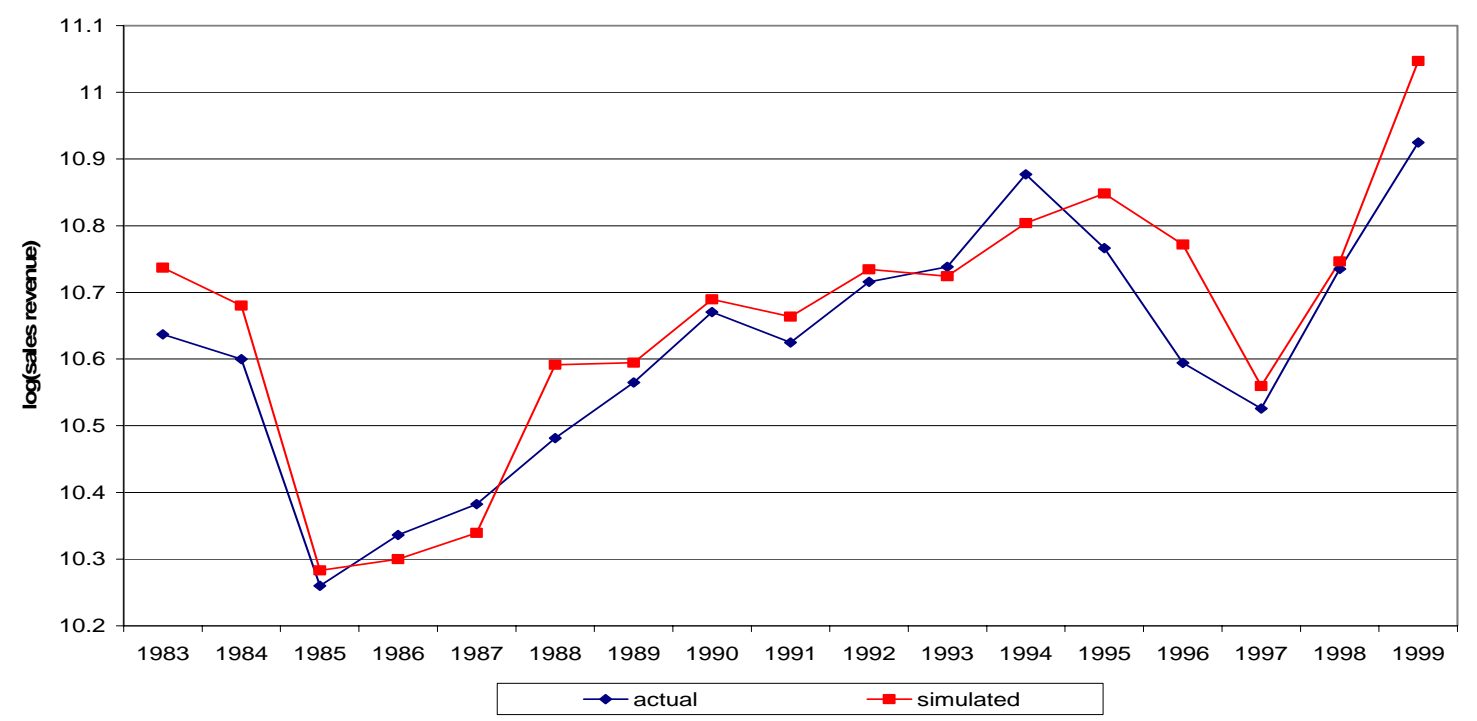

Figure 6 reports the two series for employment per plant. The model-based estimate picks up the general trends in labor use per plant well, matching the peak in 1990 followed by decline to a low point in 1997. There are two periods of overshooting, in 1990-1992 and in 19951997.

35 The Theil goodness-of-fit statistics for the four variables in this in-sample simulation are provided in appendix $\mathrm{C}$. 
Figure 6: Model Simulations, SIC 2211, Employment

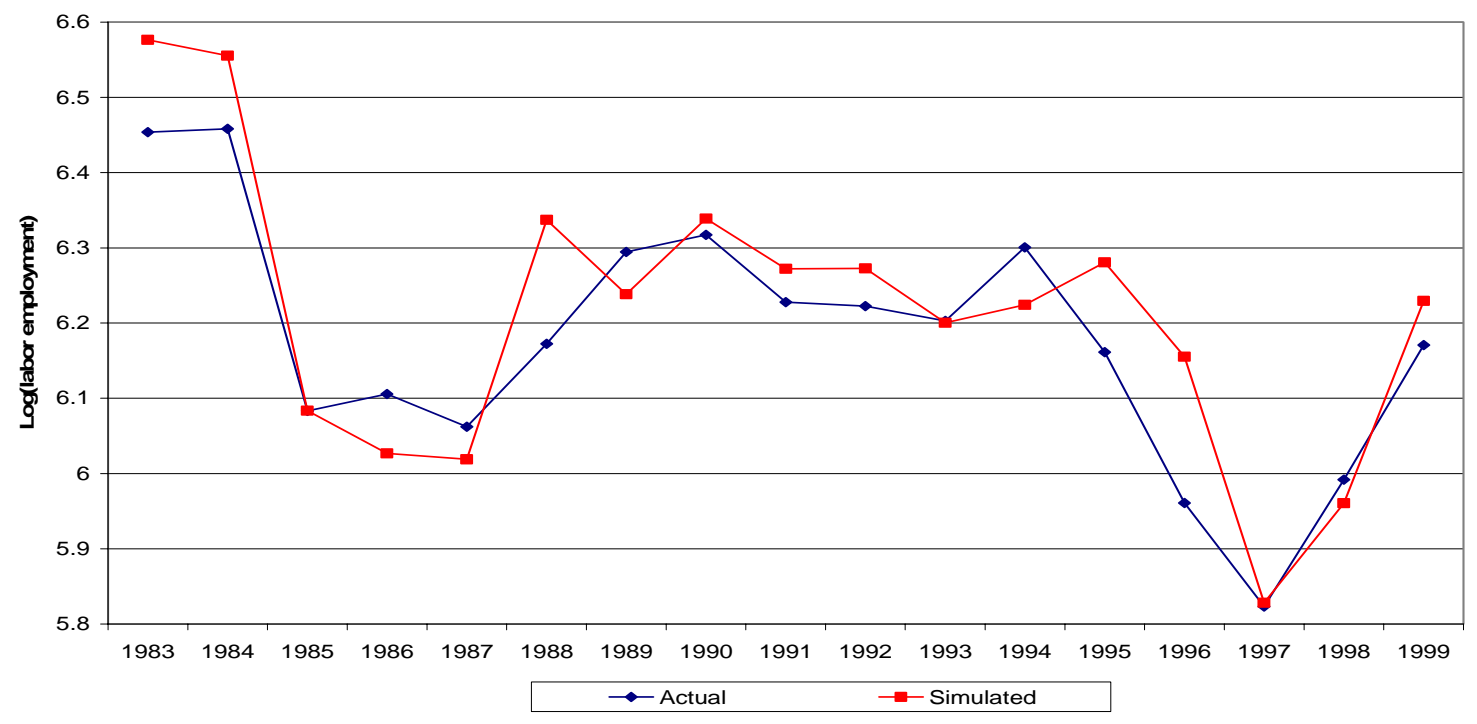

The next sets of results are the product of successive in-sample comparative-dynamic simulations, taking the simulated results illustrated in Figures 5 and 6 as the base. These results are summarized in Table 10.

- The first in-sample simulation calculates the impact of exogenous technical progress on output and employment for a plant in continuous operation. If 1982 is taken as the base year, the counterfactual assumes that exogenous technical progress continues until 1987 and is non-existent after that year. In that case, the average sales per plant in the base simulation is forecast to be 5.4 percent higher in 1999 relative to the no-technicalprogress outcome. The average employment per plant with technical progress is 42 percent below that in the absence of exogenous technological progress by 1999 . Exogenous technical progress, thus, was responsible for some sales gains in that period and also for a substantial share of the employment losses. The differential between sales gains and employment losses is due to relatively energy- and intermediate input-using nature of technical progress; these two increased by 40 percent and 10 percent, respectively, over the no-technical-progress case. 
- The second in-sample simulation examines the impact of unchanging propensity to exit on a plant. If the propensity to exit were unchanged throughout, then the sales of an average plant will be 13.8 percent less than in the base simulation by 1999 . Labor input will be 11.9 percent less, and inputs of energy and intermediate inputs will be over 14 percent less.

The model as estimated also provides a framework for considering the impact of increased import competition on plant-level production and employment. I introduce a one-time fall of 20 percent in the relative price of imported cloth for the next five years. ${ }^{36}$ This simulation is designed to represent the impact of removal of bilateral quotas on the lowest-cost suppliers under the Agreement on Clothing and Textiles. The results of the simulation for the endogenous variables are given in Part II of Table 10. I consider two variants - one in which the domestic producers do not match the price reductions, and one in which they do. I also consider these variants within two scenarios: one with continued exogenous technical progress, and one without.

When exogenous technical progress continues,

- And when domestic producers do not match the foreign price reduction, the model predicts that the value of sales at a plant in continuous operation will fall by 49.9 percent by the end of 5 years. Given that the domestic price remains unchanged, this fall in value will be entirely due to downsizing. There will be a reduction in 49.6 percent in employment, of 58 percent in energy use and of 57 percent in use of intermediate inputs.

- By contrast, when domestic producers do match the foreign price reduction the impact is a bit less severe for the plant continuously in operation. The fall in sales is 41.7 percent, with reductions of 46.9 percent in employment, 55.4 percent in energy use and 54.6

36 This 20 percent reduction is drawn from Francois and Spinager (2005, Table 16F3), who calculate "export tax equivalents" that correspond to the impact of the quota on the sale price of the exporting country. They estimate that the increases in import prices into the US from China and Vietnam in 2001 due to the quotas were 20.8 and 20.6 percent respectively. While this calculation was done using GTAP, a general-equilibrium model of world trade, it does not incorporate a price response by the US producers. 
percent in intermediate-input use. The impact of matching foreign prices is evident in the difference between sales reduction and input reduction - while the plant does not lose market share, it does face sharply higher real prices of labor, energy and intermediate inputs.

Exogenous technical progress proves to have a positive influence in this simulation. When the same simulation is undertaken without technical progress, the percent reduction in all inputs is significantly larger. Most notably, both sales and employment face a much larger percentage drop at the average plant.

While the impact of import price reductions on plant output and employment choices is important, so also is the impact of the reductions on increasing plant closures or reducing the incentives to new plants to enter this market. As Tables 4 and 5 show, the reduction in foreign price relative to domestic price will encourage exit and discourage entry, thus reducing the number of plants in equilibrium. Figure 7 reports the simulated total number of domestic plants in SIC 2211 in the aftermath of the 20 percent price shock.

Figure 7: Domestic Market Dynamics for SIC 2211 from Tables 4 and 5

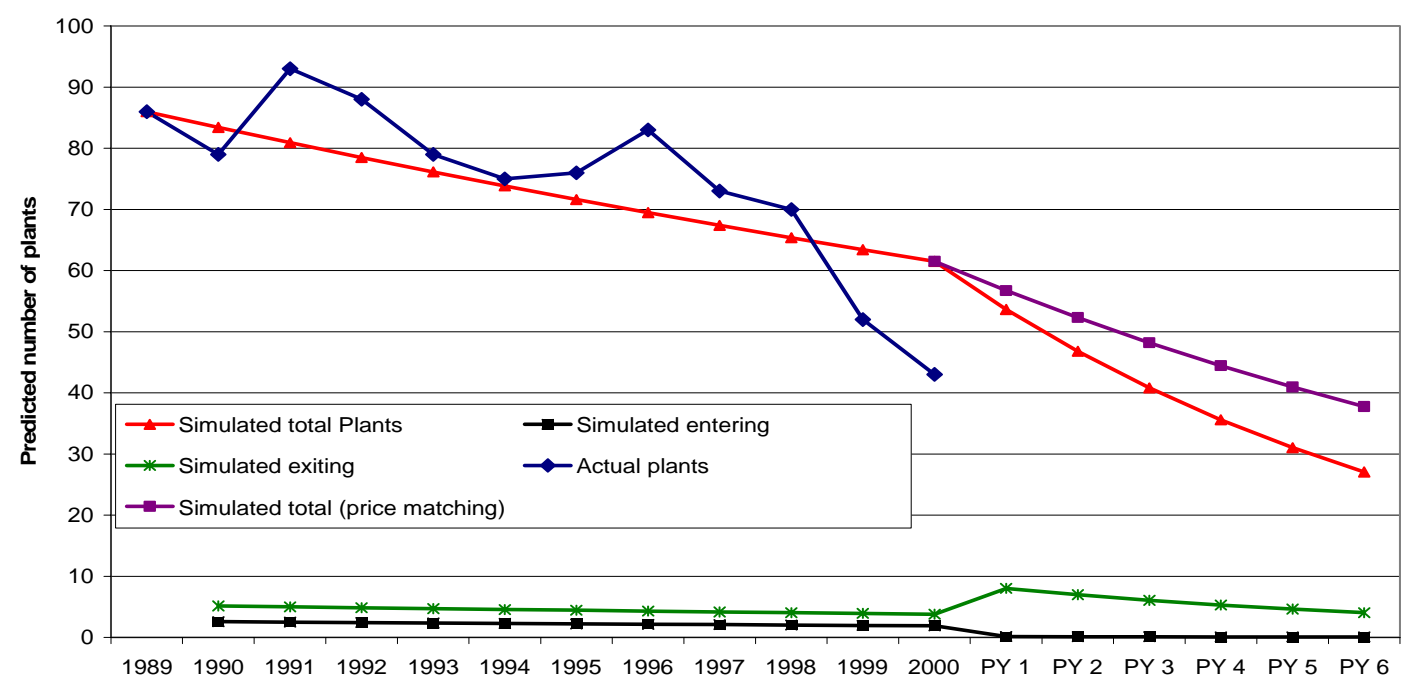


While exits accelerate with the price shock, entrants disappear. Prior to the price shock, ceteris paribus, there was a gradual reduction in the number of plants. With the price shock, this elimination of domestic plants accelerated. ${ }^{37}$

The acceleration of exit depends strongly on the plant's pricing strategy. If the plant matches the foreign price reduction, exit is less accelerated, as is evident in the "price matching" simulated total. While the matching raises the relative price of inputs, this has a less-pronounced effect on exit than does the reduction in foreign import price.

The shift in market dynamics has important consequences for technical progress and the average productivity of plants. The near-elimination of entry will reduce the potential for exogenous technical progress, as new plants with new technology are not introduced. The rapid rate of exit will increase average productivity, ceteris paribus, as those exiting are on average the least productive plants.

Table 10 presents two plant-level responses to the import-price reduction.

- The "unmatched" simulation refers to the plant-level choice not to reduce textiles prices as the price of foreign textiles falls. The results in that table indicate that plants in continuous operation should anticipate a reduction of about 50 percent in the scale of operations. In addition, there will be accelerated exit of domestic firms from the market. In equilibrium, with the new foreign import price and the same domestic product price the domestic market share will be only 11 percent. Total demand for textiles will rise with the falling price, but in the end there will be 75 percent fewer plants and the domestic plants will be producing half as much as before. Thus, the same-plant sales reductions of the previous discussion will be combined with closures of plants exceeding entry to lead to a large net reduction in both output and employment.

\footnotetext{
${ }^{37}$ PY1 through PY6 are the six years after the simulated import price reduction. Figure 7 also illustrates with the heavy (blue) line the actual number of plants observed in the US Census sample in the years from 1989 to 2000. The accelerated reduction in plants simulated to begin in 2001 actually started in 1999.
} 
- The "matched" simulation considers the case in which the domestic plants match the reduction in foreign price. As is evident in Table 10, this also leads to a sharp reduction in sales at plants in continuous operation. The reduction in final-good price raises the relative price of inputs, thus reducing the profitable scale of production for given capital stock. In this simulation the reduction in sales per plant is 41 percent, with 47 percent reduction in employment. This simulation is not characterized by accelerated plant exit.

Figure 8 illustrates the impact on domestic-plant sales of varying the degree by which the domestic plants match the foreign price reduction. The horizontal axis measures the change in pricing post-shock for the domestic plant: if the ratio is one, then the plant has matched the foreign price reduction completely, while if the ratio is 1.25 , the plant has kept its price constant in the face of the foreign price reduction.

For ratios less than 1.25, the plant has a mixed response: it has lowered its price to offset partially the reduced price of imports, thus also raising the real price of inputs. The "reduced scale of production post-shock" indicates the post-shock plant-level sales as a percent of preshock sales. The "required domestic production" indicates the scale of sales at the average plant if domestic plants were to meet demand for their goods at that post-shock price ratio. ${ }^{38}$ For smaller values of the ratio, required domestic production exceeds the desired production scale. For there to be an equilibrium at these values of the price ratio, there would have to be entry of new plants - and the earlier section demonstrated the unlikely nature of that. In the absence of new entry, the post-shock price ratio must be at least 1.075 . For each price ratio above 1.075 , the percent of existing plants that will exit is equal to the percent difference between reduced scale and required domestic production. ${ }^{39}$

38 This simulation is undertaken under the assumption that the marginal price elasticity of demand for textiles is -0.50 , so that total demand for textiles is 10 percent higher after the 20 percent import price reduction. The results are not sensitive to this assumption. Results under alternative values for the elasticity are available from the author.

39 For example, with price ratio 1.25 , the percent of existing firms that exits is $(0.49-0.12) / 0.49=0.76$. 
Figure 8: Mixed Plant-level Response to Import Price Shock

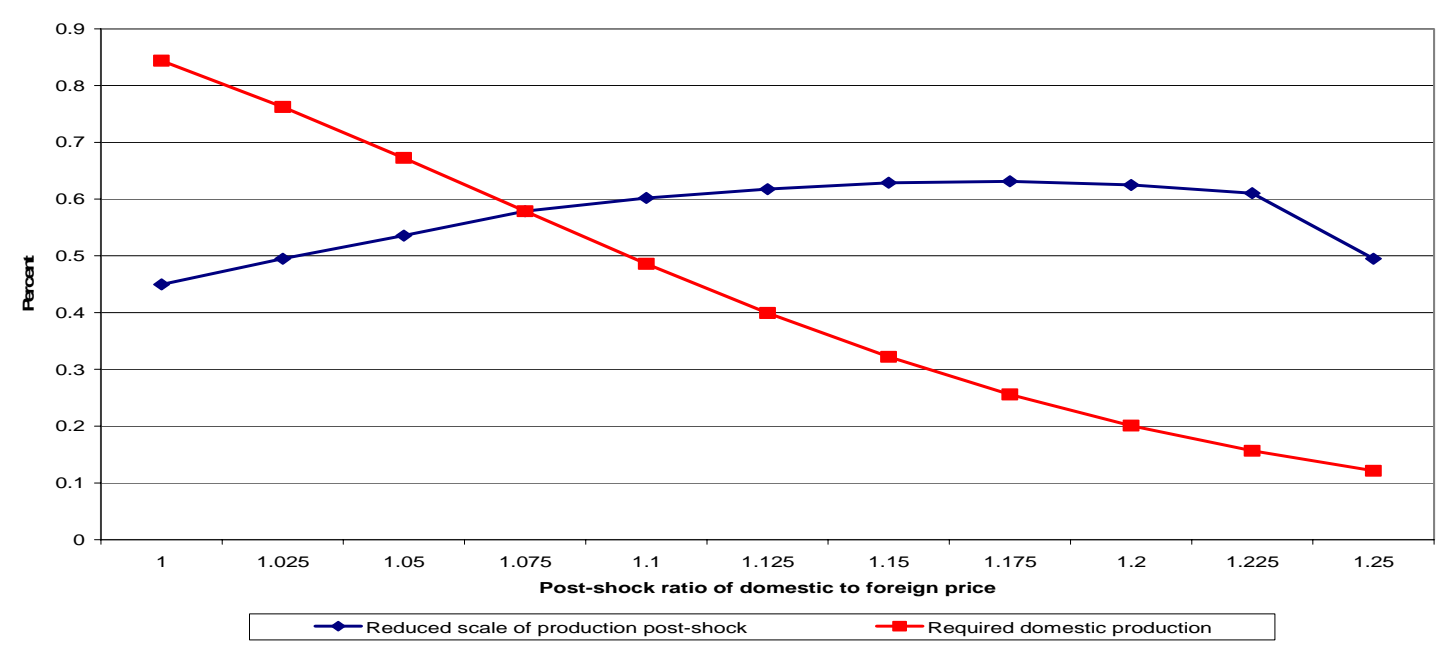

The pattern of downsizing and closure noted here is true more generally for reduced foreign import prices. Figure 9 illustrates the combinations of downsizing and closure predicted for various post-shock price ratios. Both curves are downward sloping: the optimal response for plants in this sector is to reduce production in response to reduced foreign price, and that price reduction will also trigger exit of the lower-productivity plants. As is evident from the figure, the optimal response for small increases in the ratio is for downsizing of the average plant to be more important that closure in the equilibrium response to the shock. For post-shock ratios greater than 1.17, however, closure of plants becomes the larger percentage response - although the downsizing of production at individual plants remains quite significant. 
Figure 9: Downsizing and closure after import price increases of varying sizes

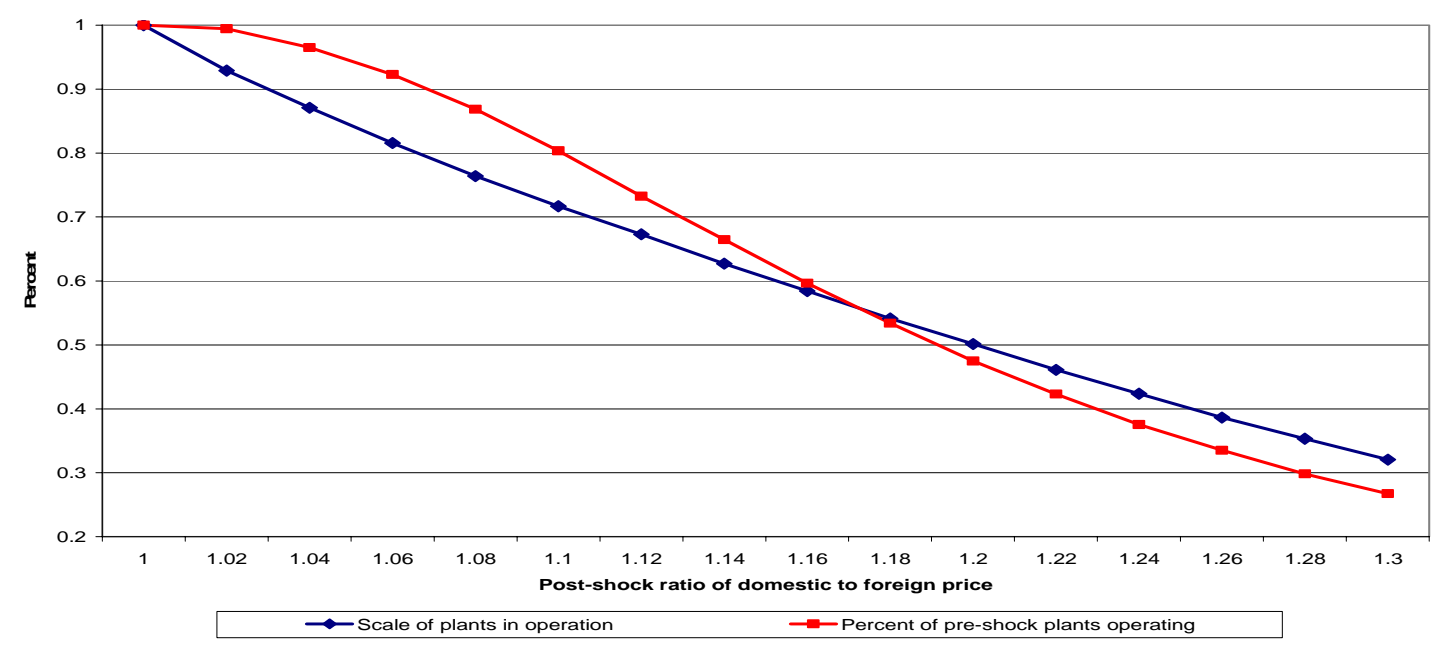

\section{Conclusions and extensions.}

Examination of the experiences of textiles plants in the US provides an important window on the phenomenon of import price competition in a mature industry. In this paper I demonstrate that it is possible to separate out the import-competition and technological-growth aspects of plant-level behavior. In the simulations reported, the import-competition effect on output and employment is strongly negative. Projections based on the evidence from 1983 to 2000 suggest that technological progress in these industries can be relied upon to provide a positive independent impetus to sales and a negative effect on employment, but these effects are much smaller quantitatively than the negative effect of import competition.

The empirical evidence for production and trade of broadwoven cotton textiles indicates that import price competition is responsible for substantial downsizing of domestic production. This in turn leads to substantial reductions in employment. While the direction of this shift was anticipated, the magnitude of downsizing implied was quite large -- whether or not the plants matched the foreign price reduction. Technical progress played an important role in both sales growth and employment reduction during the 1983-2000 period, but its effect is swamped by the impact of foreign competition in the simulations of the post-quota period. 
The simulation of plant-level response to the removal of quotas on imports illustrates the value of plant-level modeling. Not only are quantitative estimates possible for the impact of removal of quotas, but the estimates allow a decomposition of effects between technical progress, productivity shifts due to changing composition of firms, and plant-level responses to changing relative prices of imports on the domestic market. This decomposition will allow more careful consideration of effects of policy interventions on the textiles sector. While not done here, it will be a fruitful direction for future research.

The results from this exercise are sensible, but are specific to one category of textiles. It will be useful in the future to extend this to other categories of textiles and apparel. 


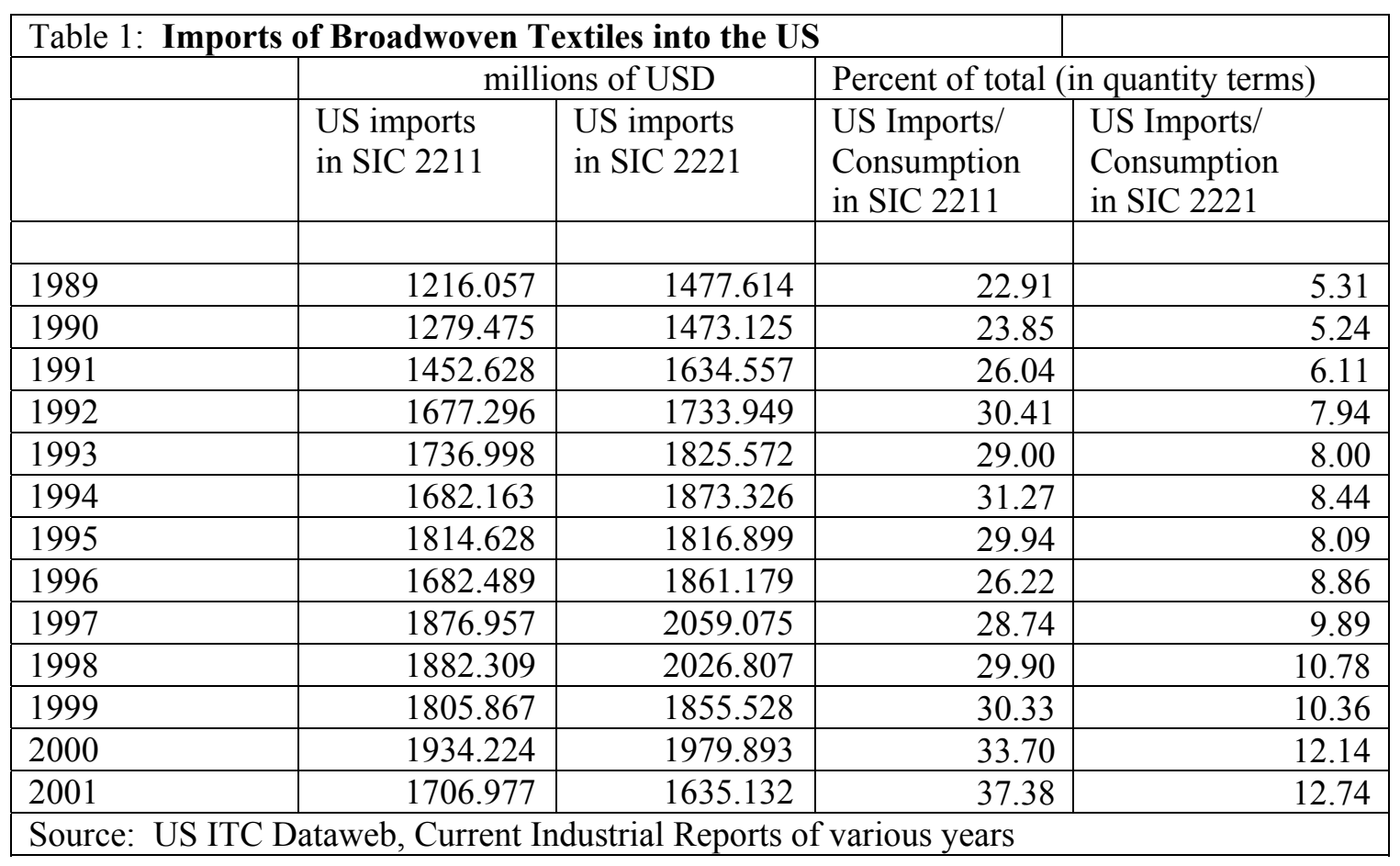


Table 2: Countries with at least one binding quota in Broadwoven cloth

Cotton

Belarus

China

India

Indonesia

Korea

Malaysia

Pakistan

Sri Lanka

Taiwan

Thailand

Turkey

United Arab Emirates

$\begin{array}{ll}\text { a } & 1993-1994, \text { binding in broad category } \\ \text { b } & 1993-1994, \text { binding in broad category } \\ \text { c } & 1993-2004, \text { binding in broad category } \\ \text { d } & 1993-2002, \text { binding in broad category } \\ \text { e } & 1993-2003, \text { binding in broad category }\end{array}$

2001-2002, 2004

1993-1994, 1998, 2001-

1993-1995, 1998-2004 2003

1993-1999

1989-2001 1989-2002

c

1993 a

1993-1995, 1997-2003

1993, 1995-2000, 2002 d

$1995-2000 \mathrm{~b}$

1993-1994, 1997-2002

1993-1995,

1998

1993-1995, 1998-1999

1993-2003 e

1993-2002

1993

Source: OTEXA, US Department of Commerce 
Table 3: Total Value of Sales (TVS), Average

\begin{tabular}{|l|l|l|l|l|}
\hline \multicolumn{1}{|c|}{ Year } & $\begin{array}{c}\text { Number of } \\
\text { Plants in SIC } \\
\mathbf{2 2 1 1}\end{array}$ & $\begin{array}{c}\text { Mean TVS in } \\
\text { SIC 2211 }\end{array}$ & $\begin{array}{c}\text { Number of } \\
\text { Plants in SIC } \\
\mathbf{2 2 2 1}\end{array}$ & $\begin{array}{c}\text { Mean TVS in } \\
\text { SIC 2221 }\end{array}$ \\
\hline $1972 *$ & 210 & 12011.90 & 306 & 11976.52 \\
\hline 1973 & 176 & 15207.03 & 254 & 15957.00 \\
\hline 1974 & 179 & 17847.63 & 267 & 17168.82 \\
\hline 1975 & 170 & 17070.59 & 269 & 16216.64 \\
\hline 1976 & 161 & 22636.18 & 271 & 20791.53 \\
\hline $1977 *$ & 191 & 22882.03 & 305 & 19567.65 \\
\hline 1978 & 164 & 24537.73 & 257 & 23946.68 \\
\hline 1979 & 154 & 30203.57 & 253 & 26486.25 \\
\hline 1980 & 150 & 33603.45 & 247 & 29338.13 \\
\hline 1981 & 136 & 37182.71 & 259 & 31393.27 \\
\hline $1982 *$ & 150 & 25786.54 & 361 & 21312.20 \\
\hline 1983 & 92 & 44673.64 & 261 & 32527.43 \\
\hline 1984 & 93 & 43576.29 & 234 & 35681.27 \\
\hline 1985 & 89 & 41169.58 & 228 & 33712.19 \\
\hline 1986 & 87 & 43735.47 & 217 & 36280.37 \\
\hline $1987 *$ & 137 & 38213.82 & 246 & 31268.73 \\
\hline 1988 & 99 & 54106.94 & 179 & 43204.39 \\
\hline 1989 & 83 & 59289.27 & 172 & 44948.77 \\
\hline 1990 & 81 & 59888.81 & 172 & 44401.02 \\
\hline 1991 & 95 & 56768.44 & 181 & 41532.23 \\
\hline $1992 *$ & 127 & 44775.19 & 240 & 35304.36 \\
\hline 1993 & 84 & 67098.13 & 177 & 45881.41 \\
\hline 1994 & 101 & 57353.34 & 174 & 46568.93 \\
\hline 1995 & 98 & 64624.70 & 170 & 49620.45 \\
\hline 1996 & 103 & 60477.65 & 164 & 50486.68 \\
\hline $1997 *$ & 142 & 41283.42 & 253 & 40693.98 \\
\hline 1998 & 99 & 60743.58 & 178 & 49816.30 \\
\hline 1999 & 89 & 57002.82 & 151 & 55240.56 \\
\hline 2000 & 46 & 41216.33 & 72 & 41216.33 \\
\hline$* 42$ & 63 & $* 2$ & \\
\hline
\end{tabular}

* Years in which the Census for Manufacturers is taken, covering a larger number of firms (by including smaller operations). In other years, data are taken from Annual Survey of Manufacturers. Source for both: US Bureau of the Census database. 


\section{Table 4: Calculation of the capital stock}

Calculation of depreciation rate from observations from 1987 to 1992 and from 1992 to 1997.

A. Complete sample: 516 observations

Nonlinear OLS Summary of Residual Errors

$\begin{array}{lclllll} & \text { DF } & \text { DF } & & & & \\ \text { Equation } & \text { Model } & \text { Error } & \text { SSE } & \text { MSE } & \text { Root MSE } & \text { R-Square } \\ \text { k } & 515 & 1.189 \mathrm{E} 11 & 2.3094 \mathrm{E} 8 & 15196.7 & 0.6388 & 0.6388\end{array}$

\begin{tabular}{|c|c|c|c|c|}
\hline Parameter & $\begin{array}{l}\text { Approx } \\
\text { Estimate }\end{array}$ & Std Err & $\begin{array}{l}\text { Approx } \\
\text { t Value }\end{array}$ & $\operatorname{Pr}>|t|$ \\
\hline & 0.907631 & 0.00450 & 201.92 & .0001 \\
\hline
\end{tabular}

Correlation of actual with calculated in

$\begin{array}{ll}1987 & 0.73 \\ 1997 & 0.80\end{array}$

B. Estimate for earlier subperiod (1987-1992, 270 observations).

\begin{tabular}{|c|c|c|c|c|c|c|}
\hline Equation & $\begin{array}{c}\text { DF } \\
\text { Model }\end{array}$ & $\begin{array}{l}\mathrm{DF} \\
\text { Error }\end{array}$ & SSE & MSE & Root MSE & R-Square \\
\hline $\mathrm{k}$ & 269 & $4.285 \mathrm{E} 10$ & $1.593 \mathrm{E} 8$ & 12621.5 & 0.6783 & 0.6783 \\
\hline & Parameter & $\begin{array}{l}\text { Approx } \\
\text { Estimate }\end{array}$ & Std Err & $\begin{array}{ll} & \text { Approx } \\
\text { t Value }\end{array}$ & $\operatorname{Pr}>|t|$ & \\
\hline & d1 & 0.884751 & 0.00548 & 161.32 & $<.000$ & \\
\hline
\end{tabular}

C. Estimate for the later subperiod (1992-1997, 246 observations)

$\begin{array}{lcclllll} & \text { DF } & \text { DF } & & & & \\ \text { Equation } & \text { Model } & \text { Error } & \text { SSE } & \text { MSE } & \text { Root MSE } & \text { R-Square } \\ \text { k } & 245 & 6.909 \mathrm{E} 10 & 2.82 \mathrm{E} 8 & 16792.8 & 0.6378 & 0.6378\end{array}$

\begin{tabular}{|c|c|c|c|c|}
\hline & Approx & & Approx & \\
\hline Parameter & Estimate & Std Err & t Value & $\operatorname{Pr}>|t|$ \\
\hline $\mathrm{d} 2$ & 0.93414 & 0.00674 & 138.60 & $<.0001$ \\
\hline
\end{tabular}

D. Correlation of actual and predicted, using subperiod depreciation rates:

$\begin{array}{ll}1987 & 0.74 \\ 1997 & 0.80\end{array}$


Table 5: Estimation of Production Technology and Market Parameters using the Translog Specification

\begin{tabular}{|c|c|c|c|c|c|c|}
\hline & \multicolumn{2}{|c|}{2211} & \multicolumn{2}{|c|}{2211} & \multicolumn{2}{|c|}{2211} \\
\hline & \multicolumn{2}{|c|}{ 1983-2001 } & \multicolumn{2}{|c|}{$1983-2001$} & \multicolumn{2}{|c|}{ 1983-2001 } \\
\hline & \multicolumn{2}{|c|}{$\mathrm{r}_{\mathrm{it}}-\mathrm{p}_{\mathrm{Dt}}$} & \multicolumn{2}{|c|}{$r_{i t}-p_{D t}$} & \multicolumn{2}{|c|}{$\mathrm{r}_{\mathrm{it}}-\mathrm{p}_{\mathrm{Dt}}$} \\
\hline & Coeff & S.E. & Coeff & S.E. & Coeff & S.E. \\
\hline $\mathrm{a}_{\mathrm{o}}$ & 1.57 & 0.090 & & & & \\
\hline$a_{k}$ & 0.24 & 0.036 & 0.20 & 0.012 & $\begin{array}{l}-0.01 \\
\end{array}$ & 0.050 \\
\hline$a_{1}$ & 0.24 & 0.051 & 0.58 & 0.008 & 0.39 & 0.029 \\
\hline$a_{e}$ & 0.03 & 0.010 & 0.01 & 0.002 & 0.04 & 0.006 \\
\hline$a_{m}$ & 0.49 & & 0.21 & & 0.53 & 0.049 \\
\hline$a_{5}$ & & & & & 0.01 & 0.005 \\
\hline$a_{6}$ & & & & & 0.04 & 0.001 \\
\hline $\mathrm{a}_{7}$ & & & & & 0.002 & 0.001 \\
\hline$a_{8}$ & & & & & 0.04 & 0.003 \\
\hline $\mathrm{a}_{9}$ & 0.10 & 0.028 & 0.13 & 0.030 & & \\
\hline$a_{10}$ & 0.001 & 0.001 & 0.001 & 0.000 & & \\
\hline $\mathrm{b}_{1}$ & -0.005 & 0.012 & 0.001 & 0.001 & -0.001 & 0.0001 \\
\hline$b_{2}$ & 0.002 & 0.002 & -0.002 & 0.0001 & -0.002 & 0.0001 \\
\hline $\mathrm{b}_{3}$ & 0.033 & 0.024 & -0.041 & 0.004 & -0.034 & 0.0006 \\
\hline $\mathrm{b}_{4}$ & -0.002 & 0.003 & -0.006 & 0.0004 & -0.027 & 0.000 \\
\hline$b_{5}$ & 0.017 & 0.021 & -0.090 & 0.001 & 0.006 & 0.002 \\
\hline $\mathrm{b}_{6}$ & -0.007 & 0.004 & -0.007 & 0.0002 & -0.076 & 0.003 \\
\hline $\mathrm{b}_{7}$ & $\begin{array}{l}-0.015 \\
\end{array}$ & 0.003 & -0.014 & 0.004 & -0.003 & 0.001 \\
\hline $\mathrm{b}_{8}$ & -0.006 & 0.001 & 0.002 & 0.0003 & 0.001 & 0.0004 \\
\hline $\mathrm{b}_{9}$ & -0.0009 & 0.0002 & -0.0007 & 0.00006 & -0.0002 & 0.0001 \\
\hline $\mathrm{b}_{10}$ & 0.008 & 0.001 & -0.002 & 0.001 & -0.001 & 0.0003 \\
\hline$\mu$ & 0.322 & 0.090 & 0.368 & 0.076 & 5.79 & 0.74 \\
\hline$\sigma$ & 144.13 & 898.0 & 14.40 & 1.08 & 14.16 & 2.13 \\
\hline $\mathrm{N}$ & 1402 & & 1402 & & 968 & \\
\hline
\end{tabular}

Coefficients significantly different from zero at the 95 percent level of confidence are presented in boldface. Coefficients $a_{5}$ through $a_{8}$ have been replaced through constant-returns-to-scale restrictions in the first two columns; see the estimating system in Appendix A for details. The first column is without fixed-effect terms while the second and third columns include plantspecific effects; those coefficients are not included in the table. The third column does not impose constant-returns-to-scale conditions, and its standard errors are obtained through bootstrapping. 
Table 6: Investment in Industry SIC 2211

\begin{tabular}{|c|c|c|c|c|}
\hline & \multicolumn{2}{|c|}{ Translog } & \multicolumn{2}{|c|}{ Cobb-Douglas } \\
\hline & Coefficient & Standard Error & Coefficient & Standard Error \\
\hline Intercept & 1.47 & 1.19 & 2.30 & 1.32 \\
\hline $\mathrm{k}_{\mathrm{t}-1}$ & 0.09 & 0.08 & 0.35 & 0.05 \\
\hline$\overline{i_{t-1}}$ & 0.44 & 0.03 & 0.44 & 0.03 \\
\hline$u_{\text {it }}$ & 0.66 & 0.14 & 0.86 & 0.24 \\
\hline cu_a $a_{t}$ & -0.04 & 0.01 & -0.05 & 0.01 \\
\hline $\mathrm{cu} \mathrm{t}_{\mathrm{t}}$ & 0.05 & 0.02 & 0.04 & 0.02 \\
\hline $\mathrm{N}$ & 961 & & 961 & \\
\hline
\end{tabular}

Coefficients in bold are significantly different from zero at 95 percent level of confidence. Bootstrapped standard errors in parentheses. These coefficients were estimated jointly with those of the second step of the two-step estimation process: up it is the same unobserved variable in both equations. Plant-specific dummy variables were also included in estimation. 
Table 7: Firm propensity to exit as a function of technological and international factors in SIC 2211.

\begin{tabular}{|l|l|l|}
\hline & Coefficient & Standard Error \\
\hline$\left(\mathrm{p}_{\mathrm{ft}}-\mathrm{p}_{\mathrm{dt}}\right)$ & $\mathbf{- 3 . 8 4}$ & 1.04 \\
\hline$\left(\mathrm{p}_{\mathrm{mt}}-\mathrm{p}_{\mathrm{dt}}\right)$ & 0.35 & 4.59 \\
\hline$\left(\mathrm{v}_{\mathrm{it}}-\mathrm{p}_{\mathrm{dt}}\right)$ & 0.19 & 0.41 \\
\hline$\left(\mathrm{w}_{\mathrm{it}}-\mathrm{p}_{\mathrm{dt}}\right)$ & 0.02 & 0.45 \\
\hline $\mathrm{k}_{\mathrm{it}}$ & -0.30 & 0.27 \\
\hline $\mathrm{i}_{\mathrm{it}}$ & -0.19 & 0.25 \\
\hline$\left(\mathrm{k}_{\mathrm{it}}\right)^{2}$ & 0.03 & 0.02 \\
\hline$\left(\mathrm{i}_{\mathrm{it}}\right)^{2}$ & 0.02 & 0.02 \\
\hline
\end{tabular}

Probit estimation. Coefficients in bold are significantly different from zero at the 95 percent level of confidence. Each probit regression also included a complete set of time and state-of-origin dummy variables. 
Table 8: Poisson regression of propensity to enter industry SIC 2211.

\begin{tabular}{|l|l|l|}
\hline & SIC 2211 & \\
\hline & Coefficient & Standard Error \\
\hline Intercept & $\mathbf{1 3 7 . 7 8}$ & 34.41 \\
\hline$\left(\mathrm{p}_{\mathrm{ft}}-\mathrm{p}_{\mathrm{dt}}\right)$ & $\mathbf{1 3 . 0 1}$ & 4.50 \\
\hline$\left(\mathrm{p}_{\mathrm{mt}}-\mathrm{p}_{\mathrm{dt}}\right)$ & $\mathbf{1 4 . 4 5}$ & 6.56 \\
\hline$\left(\mathrm{v}_{\mathrm{it}}-\mathrm{p}_{\mathrm{dt}}\right)$ & 6.77 & 4.40 \\
\hline$\left(\mathrm{w}_{\mathrm{t}}-\mathrm{p}_{\mathrm{dt}}\right)$ & $\mathbf{7 . 4 9}$ & 3.01 \\
\hline$\left(\mathrm{r}_{\mathrm{t}}-\mathrm{p}_{\mathrm{dt}}\right)$ & $\mathbf{- 1 2 . 7 1}$ & 3.52 \\
\hline $\mathrm{cu} \mathrm{a}_{\mathrm{t}}$ & -0.05 & 0.25 \\
\hline $\mathrm{cu} \mathrm{t}_{\mathrm{t}}$ & 0.10 & 0.02 \\
\hline $\mathrm{n}$ & 17 & \\
\hline
\end{tabular}

Poisson count regression. Coefficients in bold are significantly different from zero at the 95 percent level of confidence. 
Table 9: Number of firms and Inverse Mills Ratio $\left(\kappa_{\mathrm{it}}\right)$ in SIC 2211

$\begin{array}{ccc}\text { Year } & \text { Number of firms } & \text { Average Inverse Mills Ratio } \\ 1982 & 63 & 0.293993 \\ 1983 & 62 & 0.371121 \\ 1984 & 64 & 0.331815 \\ 1985 & 65 & 0.381226 \\ 1986 & 69 & 0.529837 \\ 1987 & 91 & 0.531536 \\ 1988 & 91 & 0.552644 \\ 1989 & 86 & 0.498593 \\ 1990 & 79 & 0.526548 \\ 1991 & 93 & 0.537466 \\ 1992 & 88 & 0.512334 \\ 1993 & 79 & 0.557718 \\ 1994 & 75 & 0.578690 \\ 1995 & 76 & 0.544235 \\ 1996 & 83 & 0.466658 \\ 1997 & 73 & 0.480286 \\ 1998 & 70 & 0.457162 \\ 1999 & 52 & 0.401049 \\ 2000 & 43 & 0.156904\end{array}$

Source: calculated from probit estimation reported in Table 7. 


\begin{tabular}{|c|c|c|c|c|}
\hline \multicolumn{5}{|l|}{ Part I: In-sample simulation } \\
\hline & $\ln \left(\mathrm{q}_{\mathrm{t}}\right)$ & $\ln \left(l_{t}\right)$ & $\ln \left(e_{t}\right)$ & $\ln \left(m_{t}\right)$ \\
\hline No Technical progress & -5.43 & -42.41 & 40.16 & 10.49 \\
\hline No exit & -13.82 & -11.88 & -14.12 & -14.65 \\
\hline \multicolumn{5}{|c|}{ Part II: Out-of-sample simulation -- next 5 years } \\
\hline \multicolumn{5}{|l|}{ With technical progress: } \\
\hline Lower import price (unmatched) & -49.94 & -49.58 & -58.26 & -57.44 \\
\hline Lower import price (matched) & -41.71 & -46.88 & -55.35 & -54.56 \\
\hline \multicolumn{5}{|l|}{ Without technical progress: } \\
\hline Lower import price (unmatched): & -68.89 & -69.35 & -66.04 & -73.00 \\
\hline Lower import price (matched) & -63.87 & -67.81 & -63.91 & -71.24 \\
\hline
\end{tabular}

Source: simulations using model of Table 5. 


\section{Bibliography.}

Abernathy, F., J. Dunlop, J. Hammond and D. Weil: A Stitch in Time. New York, NY: Cambridge University Press, 1999.

Baldwin, R.: "Heterogeneous Firms and Trade: Testable and Untestable Properties of the Melitz Model", NBER Working Paper 11471, June 2005.

Baldwin, R. and F. Robert-Nicoud: "Trade and Growth with Heterogeneous Firms", CEPR Discussion Paper 4965, March 2005.

Bernard, A., J. Eaton, J. Jensen and S. Kortum: "Plants and Productivity in International Trade", processed, 2000.

Bernard, A. and J. Jensen: "Exporters, Jobs and Wages in US Manufacturing: 1976-1987", Brookings Papers on Economic Activity Microeconomics, 1995, pp. 67-112.

Bernard, A. and J. Jensen: "Exceptional Exporter Performance: Cause, Effect or Both?”, Journal of International Economics 47, 1999, pp. 1-26.

Bernard, A. and J. Jensen: “Why Some Firms Export”, NBER Working Paper 8349, 2001a.

Bernard, A. and J. Jensen: "Exporting and Productivity: The Importance of Reallocation", processed, 2001b.

Bernard, A., J. Jensen and P. Schott: "Survival of the Best Fit: Competition from Low-Wage Countries and the (Uneven) Growth of US Manufacturing Plants", NBER Working Paper 9170, 2002.

Cline, W.: The Future of World Trade in Textiles and Apparel. Washington, DC: Institute for International Economics, 1987.

Conway, P.: "The Case of the Missing Trade and Other Mysteries: Comment", American Economic Review 92/1, 2002, pp. 394-404.

Conway, P. and R. Connolly: "Performance and Perception: Results from a Survey of US Textiles Manufacturers", processed, 2004.

Cooper, R.: “Comment” on "Is Trade De-Industrializing America? A Medium-Term View", Brookings Papers on Economic Activity 1, 1983, pp. 162-165.

Das, S., M. Roberts and J. Tybout: "Micro-foundations of Export Dynamics", processed, 2001.

Davis, D. and D. Weinstein: “An Account of Global Factor Trade”, American Economic Review 91/5, 2001, pp. 1423-1454.

Davis, S., J. Haltiwanger and S. Schuh: Job Creation and Destruction. Cambridge, MA: MIT Press, 1996.

Dean, J.: "The Effects of the US MFA on Small Exporters", Review of Economics and Statistics 72/1, 1990, pp. 63-69. 
Dean, J.: "Market Disruption and the Incidence of VERs under the MFA", Review of Economics and Statistics 77/2, 1995, pp. 383-388.

Devarajan, S., and D. Rodrik: "Trade Liberalization in Developing Countries: Do Imperfect Competition and Scale Economies Matter?", American Economic Review 79/2, 1989, pp. 283-287.

Dixit, A. and V. Norman: Theory of International Trade. Cambridge, UK: Nisbet Publishers, 1980 .

Dixit, A.: "Entry and Exit Decisions Under Uncertainty", Journal of Political Economy 97, 1989, pp. 620-638.

Feenstra, R.: "US Imports, 1972-1994: Data and Concordances", NBER Working Paper 5515, 1996.

Feenstra, R.: "Integration of Trade and Disintegration of Production in the Global Economy", Journal of Economic Perspectives 12/4, Fall 1998, pp. 31-50.

Francois, J. and D. Spinanger: “ATC Export Tax Equivalents”, processed, July 2005.

Freeman, R.: “Are your Wages Set in Beijing?”, Journal of Economic Perspectives 9/3, Summer 1995, pp. 15-32.

Greenstone, M.: "The Impacts of Environmental Regulations on Industrial Activity: Evidence from the 1970 and 1977 Clean Air Act Amendments and the Census of Manufacturers", NBER Working Paper 8484, September 2001.

Harrigan, J.: “Technology, Factor Supplies, and International Specialization: Estimating the Neoclassical Model”, American Economic Review 87/4, 1997, pp. 475-494.

Harrigan, J. and R. Balaban: "US Wages in General Equilibrium: The Effects of Prices, Technology and Factor Supplies, 1963-1991”, FRB-NY Staff Paper, 1999.

Johnson, G.: "Changes in Earnings Inequality: the Role of Demand Shifts", Journal of Economic Perspectives 11/2, 1997, pp. 41-54.

Katayama, H., S. Lu and J. Tybout: "Why Plant-Level Productivity Studies are Often Misleading and an Alternative Approach to Inference", processed, 2003.

Katz, L. and K. Murphy: "Changes in Relative Wages, 1963-1987: Supply and Demand Factors", Quarterly Journal of Economics 107, 1992, pp. 35-78.

Klette, T. and Z. Griliches: "The Inconsistency of Common Scale Estimators when Output Prices are Unobserved and Endogenous", Journal of Applied Econometrics 11, pp. 343361.

Lawrence, R.: "Is Trade De-Industrializing America? A Medium-Term View”, Brookings Papers on Economic Activity 1, 1983, pp. 129-161. 
Leamer, E. and J. Levinsohn: "International Trade Theory: the Evidence", chapter 26 in G. Grossman and K. Rogoff, eds.: Handbook of International Economics, volume 3. Amsterdam, NL: North-Holland, 1995.

Leibenstein, H.: "Allocative Efficiency vs 'X-efficiency", American Economic Review, vol. LVI (June, 1966), pp. 392-415.

Levinsohn, J.: "Testing the Imports-As-Market-Discipline Hypothesis", Journal of International Economics 35, 1993, pp. 1-22.

Levinsohn, J. and A. Petrin: "Estimating Production Functions using Inputs to Control for Unobservables”, NBER Working Paper 7819, 2000.

Levinsohn, J. and W. Petropoulos: "Creative Destruction or Just Plain Destruction? The US Textile and Apparel Industries Since 1972”, processed, 2001.

Lopez-Cordova, J.E.: “NAFTA and Mexico's Manufacturing Productivity: An Empirical Investigation using Micro-Level Data", processed, 2002.

Malaga, J., G. Williams and S. Fuller: "US-Mexico Fresh Vegetable Trade: the Effects of Trade Liberalization and Economic Growth", Agricultural Economics 26/1, 2001, pp. 45-55.

Maloney, W. and R. Azevado: “Trade Reform, Uncertainty and Export Promotion: Mexico 1982-1988”, Journal of Development Economics 48, 1995, pp. 67-89.

Melitz, M.: "Estimating Firm-Level Productivity in Differentiated Product Industries", processed, 2000.

Melitz, M.: “The Impact of Trade on Intra-Industry Reallocations and Aggregate Industry Productivity", Econometrica 71/6, 2003, pp. 1695-1726.

Murray, L.: "Unraveling Employment Trends in Textiles and Apparel”, Monthly Labor Review (August), 1995, pp. 62-71.

Nishimizu, M. and J. Page: “Total Factor Productivity Growth, Technological Progress, and Technical Efficiency Change: Dimensions of Productivity Change in Yugoslavia", Economic Journal 92, 1982, pp. 920-936.

Olley, S. and A. Pakes: "The Dynamics of Productivity in the Telecommunications Equipment Industry”, Econometrica 64/6, 1996, pp. 1263-1298.

Pavcnik, N.: "Trade Liberalization, Exit and Productivity Improvements: Evidence from Chilean Plants", Review of Economic Studies, forthcoming, 2003.

Revenga, A.: "Exporting Jobs? The Impact of Import Competition on Employment and Wages in US Manufacturing", Quarterly Journal of Economics 107/1, 1992, pp. 255-284.

Roberts, M. and J. Tybout: "The Decision to Export in Colombia: An Empirical Model of Entry with Sunk Costs", American Economic Review 87, 1997, pp. 545-565. 
Scott, R., T. Lee and J. Schmitt: “Trading Away Good Jobs”, Economic Policy Institute Briefing Paper, 1997.

Slaughter, M.: "International Trade and Labour-Market Outcomes: Results, Questions and Policy Options", Economic Journal 108, 1998, pp. 1452-1462.

Trefler, D.: "The Case of the Missing Trade and other Mysteries", American Economic Review 85/5, 1995, pp. 1029-1046.

Trefler, D.: "The Long and the Short of the Canada-US Free Trade Agreement", NBER Working Paper 8293, 2001.

Tybout, J.: "Plant- and Firm-Level Evidence on 'New' Trade Theories”, processed, 2001.

Tybout, J. and M. Westbrook: "Trade Liberalization and Dimensions of Efficiency Change in Mexican Manufacturing Industries", Journal of International Economics 39, 1995, pp. 5378.

Wood, A.: "Globalization and the Rise in Labor Market Inequalities", Economic Journal 108, 1998, pp. 1463-1482. 
Appendix A: Estimating equations for the translog production technology.

\section{Excluding time trend}

$$
\begin{aligned}
\ln \left(Q_{i t}\right)=a_{o}+ & a_{k} \ln K_{i t}+a_{1} \ln L_{i t}+a_{e} \ln E_{i t}+a_{m} \ln M_{i t} \\
& +a_{5} \ln K_{i t} \ln K_{i t}+a_{6} \ln L_{i t} \ln L_{i t}+a_{7} \ln E_{i t} \ln E_{i t}+a_{8} \ln M_{i t} \ln M_{i t} \\
& +b_{1} \ln K_{i t} \ln L_{i t}+b_{2} \ln K_{i t} \ln E_{i t}+b_{3} \ln K_{i t} \ln M_{i t}+b_{4} \ln L_{i t} \ln E_{i t} \\
& +b_{5} \ln L_{i t} \ln M_{i t}+b_{6} \ln E_{i t} \ln M_{i t}
\end{aligned}
$$

Sufficient conditions for constant-returns-to-scale:

$$
\begin{aligned}
& 1=a_{k}+a_{1}+a_{e}+a_{m} \\
& -2 a_{6}=b_{1}+b_{4}+b_{5} \\
& -2 a_{5}=b_{1}+b_{2}+b_{3} \\
& -2 a_{7}=b_{2}+b_{4}+b_{6} \\
& -2 a_{8}=b_{3}+b_{5}+b_{6}
\end{aligned}
$$

First-order conditions:

$$
\begin{aligned}
& a_{1}+2 a_{6} \ln L_{i t}+b_{1} \ln K_{i t}+b_{4} \ln E_{i t}+b_{5} \ln M_{i t}=W_{i t} L_{i t} / P_{i t} Q_{i t} \\
& a_{e}+2 a_{7} \ln E_{i t}+b_{2} \ln K_{i t}+b_{4} \ln L_{i t}+b_{6} \ln M_{i t}=V_{i t} E_{i t} / P_{i t} Q_{i t} \\
& a_{m}+2 a_{8} \ln M_{i t}+b_{3} \ln K_{i t}+b_{5} \ln L_{i t}+b_{6} \ln E_{i t}=P_{m i t} M_{i t} / P_{i t} Q_{i t}
\end{aligned}
$$

\section{Inclusion of time trend:}

$$
\begin{aligned}
\ln \left(Q_{i t}\right)=a_{o}+ & a_{k} \ln K_{i t}+a_{1} L_{i t}+a_{e} \ln E_{i t}+a_{m} \ln M_{i t}+a_{9} t+a_{10} t^{2} \\
& +a_{5} \ln K_{i t} \ln K_{i t}+a_{6} \ln L_{i t} \ln L_{i t}+a_{7} \ln E_{i t} \ln E_{i t}+a_{8} \ln M_{i t} \ln M_{i t} \\
& +a_{10} t^{2}+b_{1} \ln K_{i t} \ln L_{i t}+b_{2} \ln K_{i t} \ln E_{i t}+b_{3} \ln K_{i t} \ln M_{i t} \\
& +b_{4} \ln L_{i t} \ln E_{i t}+b_{5} \ln L_{i t} \ln M_{i t}+b_{6} \ln E_{i t} \ln M_{i t} \\
& +b_{7} \ln K_{i t} t+b_{8} \ln L_{i t} t+b_{9} \ln E_{i t} t+b_{10} \ln M_{i t} t
\end{aligned}
$$

Same constant-returns-to-scale restrictions:

First-order conditions:

$$
\begin{aligned}
& a_{1}+2 a_{6} \ln L_{i t}+b_{1} \ln K_{i t}+b_{4} \ln E_{i t}+b_{5} \ln M_{i t}+b_{8} t=W_{i t} L_{i t} / P_{i t} Q_{i t} \\
& a_{e}+2 a_{7} \ln E_{i t}+b_{2} \ln K_{i t}+b_{4} \ln L_{i t}+b_{6} \ln M_{i t}+b_{9} t=V_{i t} E_{i t} / P_{i t} Q_{i t} \\
& a_{m}+2 a_{8} \ln M_{i t}+b_{3} \ln K_{i t}+b_{5} \ln L_{i t}+b_{6} \ln E_{i t}+b_{10} t=P_{m i t} M_{i t} / P_{i t} Q_{i t}
\end{aligned}
$$


Table A1: Estimation of Production Technology and Market Parameters under the Cobb-Douglas restriction

\begin{tabular}{|c|c|c|c|c|c|c|}
\hline SIC category & \multicolumn{2}{|c|}{2211} & \multicolumn{2}{|c|}{2211} & \multicolumn{2}{|c|}{2211} \\
\hline & \multicolumn{2}{|c|}{ 1983-2001 } & \multicolumn{2}{|c|}{ 1983-2001 } & \multicolumn{2}{|c|}{ 1983-2001 } \\
\hline & \multicolumn{2}{|c|}{$r_{i t}-p_{D t}$} & \multicolumn{2}{|c|}{$r_{i t}-p_{D t}$} & \multicolumn{2}{|c|}{$r_{i t}-p_{D t}$} \\
\hline & Coeff & S.E. & Coeff & S.E. & Coeff & S.E. \\
\hline$a_{0}$ & 1.51 & 0.025 & & & & \\
\hline$a_{k}$ & 0.22 & 0.003 & 0.19 & 0.007 & 0.33 & 0.234 \\
\hline$a_{1}$ & 0.22 & 0.036 & 0.23 & 0.003 & 0.24 & 0.077 \\
\hline$a_{e}$ & 0.04 & 0.001 & 0.04 & 0.001 & 0.04 & 0.013 \\
\hline$a_{m}$ & 0.52 & & 0.52 & & 0.56 & 0.182 \\
\hline$\mu$ & 0.09 & 0.042 & 0.13 & 0.037 & 0.04 & 0.097 \\
\hline$\sigma$ & 36.09 & 8.380 & 10.68 & 0.760 & 7.34 & 0.420 \\
\hline $\mathrm{N}$ & 1402 & & 1402 & & 1259 & \\
\hline \multicolumn{7}{|c|}{ Number of plants: 186} \\
\hline & & & & & & \\
\hline \multirow{4}{*}{ SIC category } & \multicolumn{2}{|c|}{2221} & \multicolumn{2}{|c|}{2221} & \multicolumn{2}{|c|}{2221} \\
\hline & \multicolumn{2}{|c|}{ 1983-2001 } & \multicolumn{2}{|c|}{$1983-2001$} & \multicolumn{2}{|c|}{$1983-2001$} \\
\hline & \multicolumn{2}{|c|}{$\mathrm{r}_{\mathrm{it}}-\mathrm{p}_{\mathrm{Dt}}$} & \multicolumn{2}{|c|}{$r_{i t}-p_{D t}$} & \multicolumn{2}{|c|}{$r_{i t}-p_{D t}$} \\
\hline & Coeff & S.E. & Coeff & S.E. & Coeff & S.E. \\
\hline$a_{0}$ & 1.20 & 0.021 & & & & \\
\hline$a_{k}$ & 0.32 & 0.004 & 0.30 & 0.005 & 0.09 & 0.214 \\
\hline$a_{1}$ & 0.18 & 0.002 & 0.19 & 0.002 & 0.19 & 0.085 \\
\hline$a_{e}$ & 0.03 & 0.0004 & 0.03 & 0.0004 & 0.03 & 0.013 \\
\hline$a_{m}$ & 0.47 & & 0.48 & & 0.47 & 0.212 \\
\hline$\mu$ & 0.06 & 0.03 & 0.11 & 0.029 & 0.18 & 0.117 \\
\hline$\sigma$ & 21.05 & 2.35 & 8.98 & 0.453 & 9.15 & 0.594 \\
\hline $\mathrm{N}$ & 2866 & & 2866 & & 2591 & \\
\hline
\end{tabular}

Coefficients significantly different from zero at the 95 percent level of confidence are presented in boldface. The first column is without fixed-effect terms while the second and third columns include plant-specific effects; those coefficients are not included in the table. The third column uses the Pavcnik two-stage estimation technique and does not impose constant-returns-to-scale conditions, and the standard errors of the third column are obtained by bootstrapping. 
Table A2: Factor Shares in Total Sales Revenue in SIC 2211

\begin{tabular}{rrrrrrr} 
& TVSHIP & \multicolumn{1}{l}{$\mathrm{k} / \mathrm{q} / \mathrm{l}$} & \multicolumn{1}{l}{$\mathrm{e} / \mathrm{q}$} & $\mathrm{e} / \mathrm{p}$ & $\mathrm{w} / \mathrm{p}$ \\
1983 & 64153 & 0.513 & 0.214 & 0.031 & -3.18 & 2.7 \\
1984 & 60220 & 0.536 & 0.219 & 0.033 & -3.13 & 2.65 \\
1985 & 45870 & 0.58 & 0.228 & 0.038 & -3.03 & 2.74 \\
1986 & 48529 & 0.523 & 0.224 & 0.037 & -3 & 2.8 \\
1987 & 53674 & 0.465 & 0.214 & 0.033 & -3.06 & 2.86 \\
1988 & 53577 & 0.484 & 0.205 & 0.032 & -3.14 & 2.75 \\
1989 & 60694 & 0.504 & 0.216 & 0.035 & -3.15 & 2.84 \\
1990 & 60814 & 0.538 & 0.206 & 0.035 & -3.17 & 2.82 \\
1991 & 60317 & 0.562 & 0.21 & 0.036 & -3.18 & 2.85 \\
1992 & 65458 & 0.499 & 0.201 & 0.033 & -3.21 & 2.9 \\
1993 & 65379 & 0.496 & 0.205 & 0.032 & -3.23 & 2.95 \\
1994 & 75045 & 0.487 & 0.205 & 0.032 & -3.25 & 2.99 \\
1995 & 78338 & 0.461 & 0.19 & 0.029 & -3.28 & 2.97 \\
1996 & 74821 & 0.475 & 0.182 & 0.028 & -3.31 & 2.99 \\
1997 & 69829 & 0.482 & 0.194 & 0.029 & -3.34 & 3.08 \\
1998 & 76348 & 0.463 & 0.187 & 0.028 & -3.38 & 3.12 \\
1999 & 82115 & 0.515 & 0.187 & 0.029 & -3.42 & 3.14
\end{tabular}

Source: LRD/ASM and LRD/CM, Bureau of Census. Price ratios are defined in logarithms. 


\section{Appendix B: Data use.}

The data used in this study are drawn from the Annual Survey of Manufacturers (ASM) and from the Census of Manufactures (CM). Both are conducted by the US Bureau of the Census, with the CM collected in years ending in "2" and "7", and the ASM collected in all other years. The years used are 1982-2000 inclusive.

Two datasets are created from these files. For all years, the establishments reporting only administrative records are excluded. For the CM years, only those firms with $\mathrm{xx}=1$ are included to ensure comparability with the ASM years. The first subset is for all firms with IND=2211 (cotton textiles) and the second is for all firms with IND=2221 (manmade-fiber textiles). These correspond to the subsets by SIC codes.

In 2000, the US Bureau of the Census stopped classifying plants by SIC 2211 or SIC 2221. The new NAICS classification combines cotton and man-made broadwovens into a single category (with a few other components as well). In estimation, only those firms continuing from 1999 are used, and they are classified by their 1999 SIC code

Three industry-level price indices were imported from the Bartlesmann/Becker/Gray database:

$$
\begin{aligned}
& \mathrm{p}_{\mathrm{mt}}=\text { PIMAT }- \text { materials price index } \\
& \mathrm{p}_{\mathrm{dt}}=\text { PISHIP }- \text { price index of final goods } \\
& \mathrm{p}_{\mathrm{It}}=\text { PINV }- \text { price index for investment goods }
\end{aligned}
$$

There is one of these for each SIC code in each year through 1996. In the subsequent years, the price indices are extended by reference to the series created by Haltiwanger and published to his website.

Variables are derived from the Census data to correspond to the theoretical specification for Appendix A. The theoretical variable is given first in the table below, while the corresponding Census variables are given on the right side of the equality.

$$
\begin{aligned}
& \mathrm{L}_{\mathrm{it}}=\mathrm{TE} \\
& \mathrm{M}_{\mathrm{it}}=\mathrm{CM} / \mathrm{p}_{\mathrm{mt}} \\
& \mathrm{E}_{\mathrm{it}}=\mathrm{PE} \\
& \mathrm{W}_{\mathrm{it}}=\mathrm{SW} / \mathrm{TE} \\
& \mathrm{V}_{\mathrm{it}}=\mathrm{EE} / \mathrm{PE} \\
& \mathrm{I}_{\mathrm{it}}=\mathrm{TCE} / \mathrm{p}_{\mathrm{It}} \\
& \mathrm{Q}_{\mathrm{it}}=\mathrm{TVS} / \mathrm{p}_{\mathrm{dt}}
\end{aligned}
$$

There is one of these for each plant in each year. Time $(\mathrm{t})$ is measured as well:

$$
\mathrm{t}=\text { Year }-1980 .
$$


The variable $\mathrm{p}_{\mathrm{ft}}$ is created as an industry-specific unit value of imports in that 4-digit SIC code. It is calculated from the data maintained by Feenstra and Schott on US import value and quantity. There is one of these for each SIC code in each year.

Each establishment is assigned a unique plant number, referred to as "count". This "count" is used to create a fixed-effect array used in estimation. Also created are variables "contin", "exit" and "enter", binary variables indicating whether the plant continues operation, exits in the next period, or enters this period.

The technology specifications use four inputs $\left(\mathrm{L}_{\mathrm{it}}, \mathrm{K}_{\mathrm{it}}, \mathrm{E}_{\mathrm{it}}, \mathrm{M}_{\mathrm{it}}\right)$, plant-specific productivity effects and $t$ as a proxy for the common trend in technology. The associated first-order conditions introduce relative prices $\mathrm{w}_{\mathrm{it}}, \mathrm{p}_{\mathrm{eit}}, \mathrm{p}_{\mathrm{mt}}$. . The impact of foreign price competition in the imperfectly competitive market is modeled by $\left(\mathrm{p}_{\mathrm{ft}}-\mathrm{p}_{\mathrm{dt}}\right)$. 
Appendix C: Theil Decomposition of Simulation Results

\section{Descriptive Statistics}

\begin{tabular}{|c|c|c|c|c|c|c|}
\hline \multirow[b]{2}{*}{ Variable } & \multirow[b]{2}{*}{ N Obs } & \multicolumn{2}{|r|}{ Actual } & \multicolumn{3}{|c|}{ Predicted } \\
\hline & & $N$ & Mean & Std Dev & Mean & Std Dev \\
\hline Iprodn & 1098 & 1098 & 10.6085 & 0.9503 & 10.6458 & 0.497 \\
\hline Ipe & 1098 & 1098 & 10.4307 & 1.112 & 10.4818 & 0.6576 \\
\hline Imm & 1098 & 1098 & 9.9117 & 1.0479 & 9.9485 & 0.5385 \\
\hline Ite & 1098 & 1098 & 6.1642 & 0.8663 & 6.1974 & 0.4874 \\
\hline
\end{tabular}

\section{Statistics of fit}

\begin{tabular}{|c|c|c|c|c|c|c|c|c|}
\hline Variable & $\mathrm{N}$ & $\begin{array}{l}\text { Mean } \\
\text { Error }\end{array}$ & $\begin{array}{l}\text { Mean \% } \\
\text { Error }\end{array}$ & $\begin{array}{l}\text { Mean Abs } \\
\text { Error }\end{array}$ & $\begin{array}{l}\text { Mean Abs } \\
\% \text { Error }\end{array}$ & $\begin{array}{l}\text { RMS } \\
\text { Error }\end{array}$ & $\begin{array}{l}\text { RMS \% } \\
\text { Error }\end{array}$ & R-Square \\
\hline odn & 1098 & 0.0373 & 0.9583 & 0.5452 & 5.3587 & 0.7275 & 7.9074 & 0.4134 \\
\hline . & 1098 & 0.0512 & 1.3024 & 0.503 & 5.3473 & 0.7215 & 8.9245 & 0.5786 \\
\hline $\mathrm{m}$ & 1098 & 0.0368 & 1.275 & 0.5897 & 6.3395 & 0.8027 & 10.0968 & 0.4127 \\
\hline It & 1098 & 0.0332 & 2.3124 & 0.5002 & 8.9853 & 0.6808 & 15.8608 & 0.3818 \\
\hline
\end{tabular}

Theil Forecast Error Statistics

MSE Decomposition Proportions

\begin{tabular}{|c|c|c|c|c|c|c|c|c|c|c|}
\hline Variable & $\mathrm{N}$ & MSE & $\begin{array}{l}\text { Corr } \\
(R)\end{array}$ & $\begin{array}{l}\text { Bias } \\
\text { (UM) }\end{array}$ & $\begin{array}{l}\text { Reg } \\
\text { (UR) }\end{array}$ & $\begin{array}{l}\text { Dist } \\
\text { (UD) }\end{array}$ & $\begin{array}{l}\text { Var } \\
\text { (US) }\end{array}$ & $\begin{array}{l}\text { Covar } \\
\text { (UC) }\end{array}$ & $\begin{array}{l}\text { Inequality } \\
\text { U1 }\end{array}$ & $\begin{array}{l}\text { Coef } \\
U\end{array}$ \\
\hline odn & 1098 & 0.5293 & 0.66 & 0 & 0.03 & 0.97 & 0.39 & 0.61 & 0.0683 & 0.0341 \\
\hline 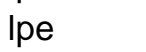 & 1098 & 0.5206 & 0.79 & 0.01 & 0.09 & 0.9 & 0.4 & 0.6 & 0.0688 & 0.0344 \\
\hline $\mathrm{m}$ & 1098 & 0.6443 & 0.66 & 0 & 0.04 & 0.96 & 0.4 & 0.6 & 0.0805 & 0.0403 \\
\hline 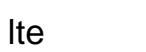 & 1098 & 0.4635 & 0.62 & 0 & 0.01 & 0.99 & 0.31 & 0.69 & 0.1094 & 0.0547 \\
\hline
\end{tabular}


Appendix D: Source of imports to the US in SIC 2211 and SIC 2221.

The developed-country share of imports was declining over time in both classifications, it declined more rapidly for SIC 2221.

$\begin{array}{ccc}\begin{array}{r}\text { Table D1: Developed-country share in total US imports } \\ \text { Year }\end{array} & \begin{array}{c}\text { Developed country share: } \\ \text { Developed country share: }\end{array} \\ & \mathbf{2 2 1 1} & \mathbf{2 2 2 1} \\ 1989 & 0.29 & 0.63 \\ 1990 & 0.29 & 0.60 \\ 1991 & 0.26 & 0.57 \\ 1992 & 0.28 & 0.55 \\ 1993 & 0.29 & 0.50 \\ 1994 & 0.30 & 0.52 \\ 1995 & 0.28 & 0.48 \\ 1996 & 0.29 & 0.47 \\ 1997 & 0.26 & 0.44 \\ 1998 & 0.26 & 0.44 \\ 1999 & 0.25 & 0.45 \\ 2000 & 0.24 & 0.43 \\ 2001 & 0.24 & 0.44\end{array}$

Source: US ITC Dataweb

It is reasonable to assume that the goods exported from developed countries will have different quality or characteristics from those exported from LDCs. When the universe of exporters is divided in this way and unit values calculated for the sub-groups, it becomes evident that the pattern of import competition observed in SIC 2211 above is also evident for SIC 2221 goods coming from developing countries. Figure D1 is an expansion of the information in Figure 2, with the unit values for imports decomposed into two parts - the unit value for developed exporters and the unit value for developing (LDC) exporter. 
Figure D1: Unit Value of Textile Imports by source

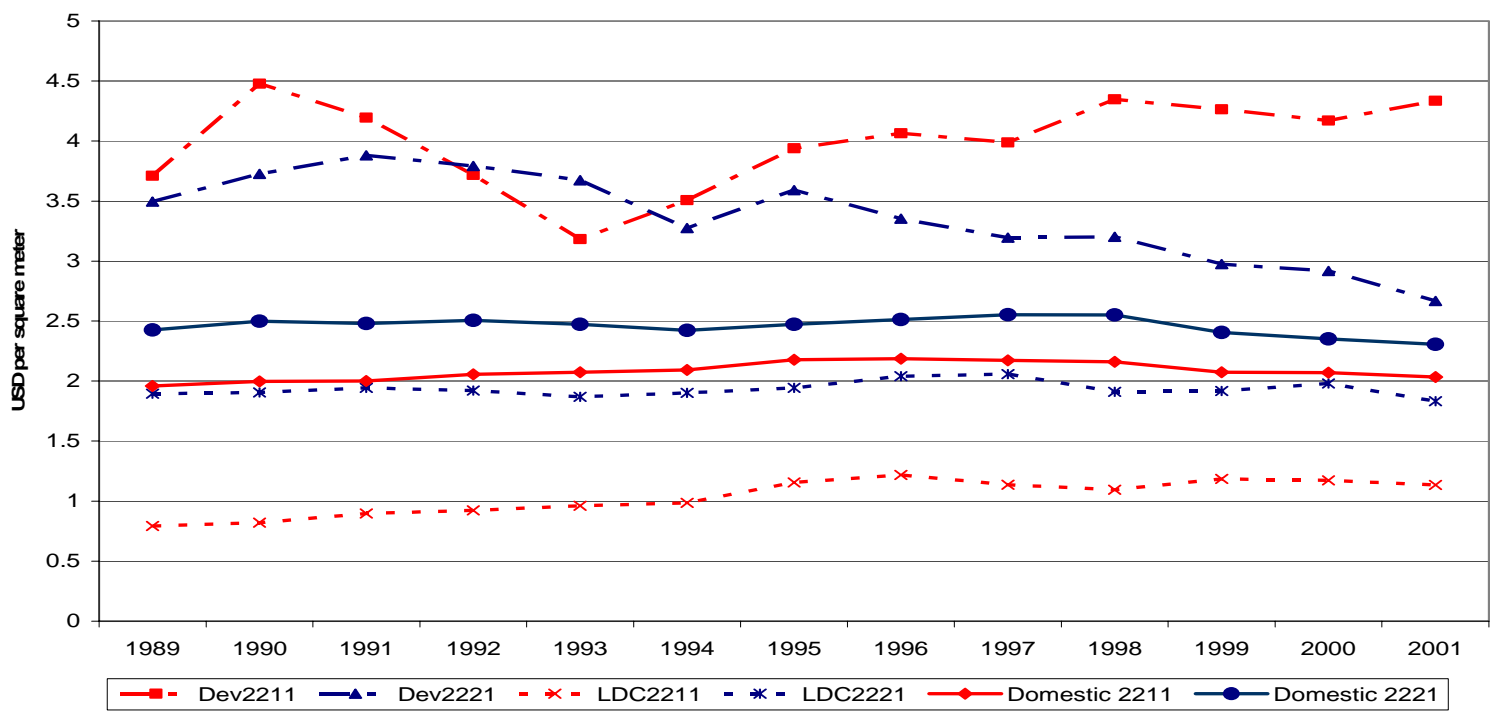

Source: US ITC Dataweb, and Figure 2

The blue lines represent the domestic and foreign unit values in classification SIC 2221. The solid blue line is the same domestic unit value found in Figure 2, while the dotted blue line below it is the unit value of imports from developing countries. The dashed blue line above indicates the unit value of imports from developed countries. The developed-country behavior provides the SIC 2221 import unit value with its distinctive downward slope, while developing-country unit values follow the slight humped shape familiar from the domestic prices. The same distinction is evident in the red lines for classification SIC 2211. Developed-country unit values are much higher than domestic price, and more volatile; developing-country unit values are much below domestic price and gradually converging.

Figure D2 illustrates the unit value and share of US imports for the countries with more than 1 percent of the import total in 2000 in SIC 2211. As is evident, there are three categories of suppliers. The low-cost suppliers have unit values of less than 1 USD. These include Pakistan, China, and India (as well as Thailand, Indonesia, Turkey and Malaysia), and they hold the largest share of the import market. The premium suppliers are those with unit values between USD 1.50 and 2.00: Hong Kong, Mexico, Taiwan (as well as South Korea and Canada). The super-premium suppliers have unit values greater than USD 2.00: Italy, UK, France (and Germany, Japan and Spain). With the domestic price at roughly USD 2.00, the super-premium suppliers are evidently selling very differentiated products. 
Figure D2: Unit Value and Import Share in SIC 2211

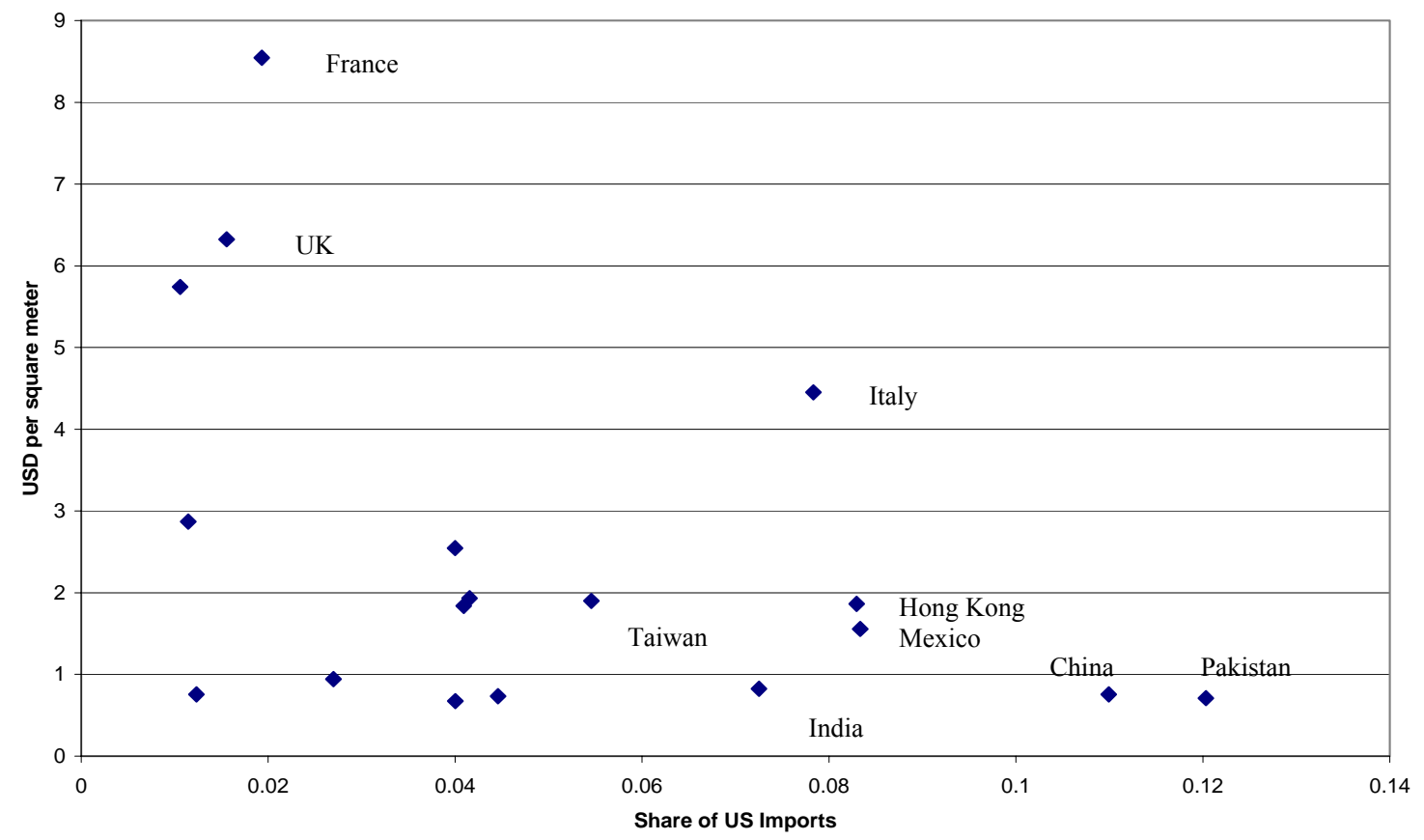

Source: US ITC Dataweb

Figure D3 provides a similar picture for US imports in 2000 in classification SIC 2221. There are a number of low-cost suppliers (i.e., cost less than USD 1.00) with smaller market shares: Turkey as well as Thailand, Philippines, Pakistan, Malaysia and Indonesia. 
Figure D3: Unit Values and Share of US Imports in SIC 2221

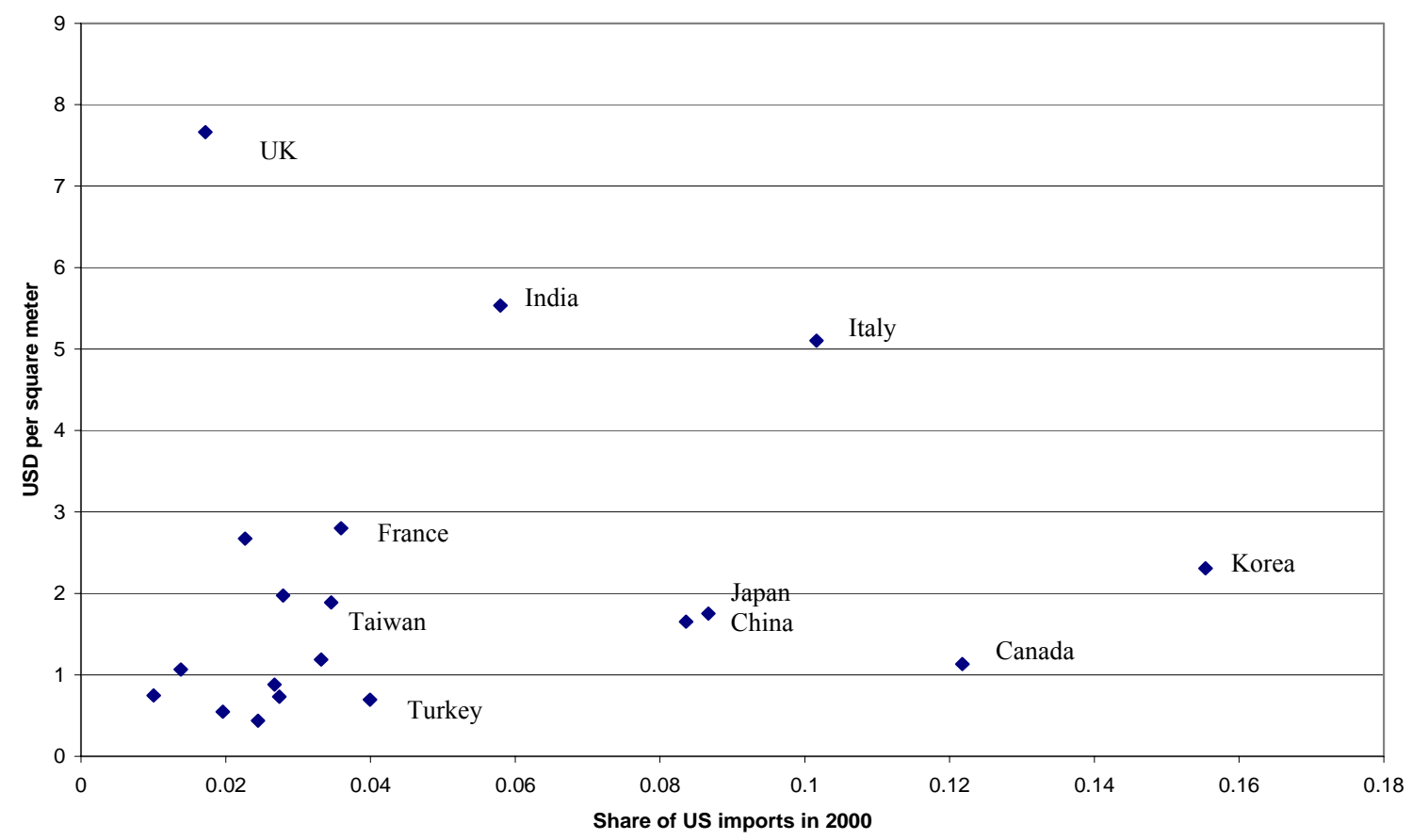

Source: US ITC Dataweb

US imports, though, come predominantly from the premium producers (USD 1.00 to USD 2.50): Korea, Canada, Japan, China, Taiwan (as well as Mexico, Belgium and Sri Lanka). The super-premium suppliers are Italy, France, UK, India (and Germany). This focus upon the premium suppliers in 2000 represents a shift from the beginning of the sample; in 1989 the dominant suppliers were Italy, Germany and France from the superpremium group. 